Article

\title{
Ferrierite and Its Delaminated and Silica-Intercalated Forms Modified with Copper as Effective Catalysts for $\mathrm{NH}_{3}$-SCR Process
}

\author{
Aneta Święs ${ }^{1}$, Andrzej Kowalczyk ${ }^{1}{ }^{\circledR}$, Małgorzata Rutkowska ${ }^{1}$, Urbano Díaz ${ }^{2}{ }^{\circledR}$, \\ Antonio E. Palomares ${ }^{2}$ a and Lucjan Chmielarz ${ }^{1, *(D)}$ \\ 1 Faculty of Chemistry, Jagiellonian University in Kraków, Gronostajowa 2, 30-387 Kraków, Poland; \\ aneta.swies@doctoral.uj.edu.pl (A.Ś.); kowalczy@chemia.uj.edu.pl (A.K.); ma.rutkows@gmail.com (M.R.) \\ 2 Instituto de Tecnología Química, Universitat Politècnica de València- \\ Consejo Superior de Investigaciones Científicas, Avd. de los Naranjos s/n, 46022 Valencia, Spain; \\ udiaz@itq.upv.es (U.D.); apalomar@iqn.upv.es (A.E.P.) \\ * Correspondence: chmielar@chemia.uj.edu.pl
}

Received: 12 June 2020; Accepted: 30 June 2020; Published: 2 July 2020

\begin{abstract}
The main goal of the study was the development of effective catalysts for the low-temperature selective catalytic reduction of $\mathrm{NO}$ with ammonia $\left(\mathrm{NH}_{3}-\mathrm{SCR}\right)$, based on ferrierite (FER) and its delaminated (ITQ-6) and silica-intercalated (ITQ-36) forms modified with copper. The copper exchange zeolitic samples, with the intended framework Si/Al ratio of 30 and 50, were synthetized and characterized with respect to their chemical composition (ICP-OES), structure (XRD), texture (low-temperature $\mathrm{N}_{2}$ adsorption), form and aggregation of deposited copper species (UV-vis-DRS), surface acidity ( $\left.\mathrm{NH}_{3}-\mathrm{TPD}\right)$ and reducibility $\left(\mathrm{H}_{2}-\mathrm{TPR}\right)$. The samples of the Cu-ITQ-6 and $\mathrm{Cu}-\mathrm{ITQ}-36$ series were found to be significantly more active $\mathrm{NH}_{3}-\mathrm{SCR}$ catalysts compared to $\mathrm{Cu}-\mathrm{FER}$. The activity of these catalysts in low-temperature $\mathrm{NH}_{3}$-SCR was assigned to the significant contribution of highly dispersed copper species (monomeric cations and small oligomeric species) catalytically active in the oxidation of $\mathrm{NO}$ to $\mathrm{NO}_{2}$, which is necessary for fast-SCR. The zeolitic catalysts, with the higher framework alumina content, were more effective in high-temperature $\mathrm{NH}_{3}$-SCR due to their limited catalytic activity in the side reaction of ammonia oxidation.
\end{abstract}

Keywords: $\mathrm{NH}_{3}-\mathrm{SCR}$; ferrierite; ITQ-6; ITQ-36; copper

\section{Introduction}

Nitrogen oxides $\left(\mathrm{NO}_{\mathrm{x}}\right)$ belong to the most dangerous air pollutants responsible for various environmental problems, such as photochemical smog, acid rain and ozone depletion. Moreover, $\mathrm{NO}_{x}$ emission contributes to the global warming problem. Nitrogen oxides are formed mainly as side-products of fossil fuel combustion in power plants, vehicles and factories. Thus, various technologies, including the optimization of the fuel combustion process and post-combustion technologies, used for the elimination of $\mathrm{NO}_{x}$ from flue gases, were developed and implemented [1]. Among the post-combustion technologies of $\mathrm{NO}_{\mathrm{x}}$ emission control, the selective catalytic reduction of nitrogen oxides with ammonia $\left(\mathrm{NH}_{3}-\mathrm{SCR}\right)$ is one of the most important methods. In this case, $\mathrm{NO}_{x}$ present in flue gases are selectively reduced by ammonia to dinitrogen and water vapor, which are the desired products of this process. This technology was first applied in Japan in the 1970s for the conversion of $\mathrm{NO}_{x}$ emitted by electric power stations and has since spread to the USA, Europe and several Asian countries [2]. The major industrial catalyst for $\mathrm{NH}_{3}-\mathrm{SCR}$ is based on the $\mathrm{V}_{2} \mathrm{O}_{5}-\mathrm{WO}_{3} / \mathrm{TiO}_{2}$ metal oxide system and effectively operates in a relatively narrow temperature range from 300 to $400{ }^{\circ} \mathrm{C}$ [2-4]. At temperatures below $300^{\circ} \mathrm{C}$, the efficiency level of $\mathrm{NO}_{\mathrm{x}}$ conversion is not satisfying, 
but while above $400{ }^{\circ} \mathrm{C}$ the side reaction of direct ammonia oxidation decreases the efficiency of $\mathrm{NO}_{\mathrm{x}}$ conversion. Industrial $\mathrm{NH}_{3}$-SCR catalysts are used mainly in the form of monoliths, located upstream of electrostatic precipitator (ESP). Therefore, such units for $\mathrm{NO}_{\mathrm{x}}$ conversion operate with dusty gas stream (high-dust SCR), which may result in the clogging of channels in monolith by particles of dust. To avoid this problem, flue gases prior to the $\mathrm{NH}_{3}$-SCR unit, should be dedusted in the ESP unit (low-dust SCR). The disadvantage of such a solution is the relatively low temperature of flue gasesabout $250^{\circ} \mathrm{C}$ or even lower, downstream of EPS [5]. Thus, for the low-dust SCR technology development of the $\mathrm{NH}_{3}-\mathrm{SCR}$ catalysts, effective operation at a temperature lower than $250{ }^{\circ} \mathrm{C}$ is necessary. Copper belongs among the most promising active components of the low-temperature $\mathrm{NH}_{3}-\mathrm{SCR}$ catalysts [1], especially in the case of copper deposited into zeolites [6-10]. It is not surprising, taking into account the ion-exchange properties of zeolites important for the deposition of metal in highly dispersed forms, surface acidity important for chemisorption and the activation of basic ammonia molecules, high surface area and uniform porous structure important to generate large number of active sites. The catalytic activity of copper strongly depends on its form and aggregation. Monomeric copper cations in the ion-exchange positions of the zeolitic framework are reported to be catalytically active in low-temperature $\mathrm{NH}_{3}-\mathrm{SCR}$ [11-13]. Shan et al. [11] reported that monomeric $\mathrm{Cu}^{2+}$ cations in $\mathrm{Cu}-\mathrm{SSZ}-13$ zeolites are catalytically active in the oxidation of $\mathrm{NO}$ to $\mathrm{NO}_{2}$, which is necessary for fast-SCR $\left(2 \mathrm{NH}_{3}+\mathrm{NO}+\mathrm{NO}_{2} \rightarrow 2 \mathrm{~N}_{2}+3 \mathrm{H}_{2} \mathrm{O}\right)$, important for low-temperature $\mathrm{NH}_{3}-\mathrm{SCR}$. On the other hand, it was reported that aggregated $\mathrm{CuO}$ species are significantly less active in the $\mathrm{NO}_{2}$ formation [11]. Clark et al. [12] reported that stable solvated $\mathrm{Cu}^{+}$cations are responsible for the limitation of low-temperature $\mathrm{NH}_{3}$-SCR efficiency, while at higher temperature, the reduction of $\mathrm{Cu}^{2+}$ to $\mathrm{Cu}^{+}$is the rate limiting step in the case of $\mathrm{Cu}$-exchanged small-pore SSZ-13 zeolites. Another problem related to the application of small pore zeolites, such as $\mathrm{Cu}-\mathrm{SSZ}-13$, in $\mathrm{NH}_{3}-\mathrm{SCR}$ is the possible aggregation of $\mathrm{Cu}$-species with the formation of bulky $\mathrm{CuO}$ aggregates, which not only decrease catalytic activity, but may also result in the destruction of the zeolite skeleton and lead to a breakdown in the long-range order of its structure [13]. Thus, copper is very promising in low-temperature $\mathrm{NH}_{3}$-SCR, but the controlled deposition of active metal species is necessary. The high-temperature $\mathrm{NH}_{3}$-SCR process is limited by the side reaction of direct ammonia oxidation by oxygen present in flue gases. Thus, the $\mathrm{NH}_{3}$-SCR catalysts operating in the high-temperature range should be active in $\mathrm{NO}_{x}$ reduction with ammonia and should be inactive in direct ammonia oxidation. The formulation of such catalyst is a demanding task, because in both these processes ammonia chemisorption and activation is one of the main steps in the majority-postulated reaction mechanisms of $\mathrm{NH}_{3}$-SCR [2] and ammonia oxidation (AMOx) [14].

Recently, layered zeolites with delaminated or intercalated structures aroused great interest as catalysts [15] or catalytic supports [16,17], due to the increased rate of internal diffusion. Delaminated layered zeolites consist of ordered zeolite layers, which are chaotically oriented, forming a so called "house of cards" structure with the bimodal pore structure. Micropores are located in zeolite layers, while the larger pores are interlayer spaces. Pillared layered zeolites can be produced by the surfactant directed method. In this case amorphous silica aggregates are deposited into the interlayer space of swollen layered zeolite precursors, which, during calcination, are converted into stable silica pillars, which permanently open interlayer space in the zeolitic sample. Such zeolites are characterized by bimodal porous structure-micropores in zeolitic layers and larger pores in interlayer spaces. It should be mentioned that not only pure silica pillars can be intercalated into the interlayer space of zeolites but the successful intercalation of multicomponent pillars into layered zeolites was also reported (e.g., silica-titania pillars [18]). As previously mentioned, zeolitic materials with the hierarchical porous structure are very promising due to the increased rate of internal diffusion, which is important for the overall reaction rate. However, our recent studies $[7,19]$ proved that the deposition of metal species in highly dispersed form was more effective for MFI zeolites with micro-mesoporous structures than for classical microporous MFI zeolites. It is very important to assume that the form and aggregation of the deposited metal play a crucial role in the $\mathrm{NH}_{3}-\mathrm{SCR}$ process. 
The presented study reports the catalytic properties of copper modified ferrierite and its delaminated (ITQ-6) and silica-intercalated (ITQ-36) forms in the $\mathrm{NH}_{3}$-SCR process and associated reactions of $\mathrm{NO}$ to $\mathrm{NO}_{2}$ oxidation and ammonia oxidation (AMOx). The influence of porous structure, $\mathrm{Si} / \mathrm{Al}$ ratio, as well as the form and aggregation of copper species introduced into the zeolitic samples, were analyzed and discussed.

\section{Results and Discussion}

\subsection{Characterization of Catalyst Precursors and Catalysts}

The zeolites were obtained from two layered precursors (PREFER) with the intended molar Si/Al ratios of 30 (PREFER_30) and 50 (PREFER_50). The calcination of such precursors resulted in the condensation of layers with the formation three dimensional (3D) microporous ferrierite zeolites (FER_30 and FER_50). The second part of the zeolite precursors was swollen with alkylammonium surfactants to open interlayer space for the intercalation of the silica pillars precursor (tetraethyl orthosilicate, TEOS), which after calcination resulted in ITQ-36_30 and ITQ-36_50 (depending on the intended Si/Al ratio in the zeolite framework). On the other hand, swollen PREFER_30 and PREFER_50, after sonication and calcination, resulted in delaminated ITQ-6_30 and ITQ-6_50 zeolites, respectively.

The process of PREFER swelling, condensation, delamination and pillaring was monitored by the X-ray diffraction method, as shown in Figure 1. In the diffractograms of the layered precursors, the (200) reflection at $2 \Theta=6.8^{\circ}$, corresponding to the interlayer distance of about $1.3 \mathrm{~nm}$, was identified [20]. After the swelling of PREFER_30 with surfactant, the main (200) reflection was shifted to $2 \Theta$ at about $3.0^{\circ}$, indicating the successful intercalation of the surfactants into the interlayer space of zeolites and resulting in the extending of the interlayer distance to about $2.1 \mathrm{~nm}$. This interlayer distance is very close to the length of the hexadecyltrimethylammonium cations $\left(\mathrm{CTMA}^{+}\right)$, indicating that the surfactant molecules are oriented perpendicularly to the zeolite layers. Apart from the main (200) reflections, the diffraction peaks at $2 \Theta$ at about $6.0,6.8$ and $8.9^{\circ}$, characteristic of the parallel ordering of the zeolite layers, are also present in the diffractogram of the swollen PREFER_30 sample. The first diffraction peak indicates the extension of the interlayer distance to about $1.5 \mathrm{~nm}$ and shows that part of the zeolite was intercalated with the surfactant molecules oriented non-perpendicularly to the zeolite layers [15]. The diffraction peak at $6.8^{\circ}$ corresponds to a small fraction of the PREFER_30 sample, which was not swollen, while the diffraction peak at $8.9^{\circ}$ is possibly related to the partially condensed zeolite layers. The swelling process causes a structural disorder in PREFER_30 indicated by broadening peaks and the loss of their intensities. The calcination of PREFER_30 resulted in a shift in the (200) reflection to $9.7^{\circ}$. The high intensity of this basal reflection, as well as the diffraction peaks characteristic of the 3-dimensional (3D) structure of ferrierite, indicates the successful synthesis of this zeolite (FER_30). The sonication of swelled PREFER_30 in acidic conditions, followed by calcination, resulted in a nearly completely delaminated structure (non-parallel ordering of the zeolite layers). The low-intensive reflection at $9.7^{\circ}$ indicates that part of the zeolite layers was condensed with the formation of ferrierite. However, the comparison of this reflection intensity in diffractograms of FER_30 and ITQ-6_30 shows that the contribution of the ferrierite in the delaminated ITQ-6_30 sample is relatively small. The intercalation of swollen PREFER_30 with silica pillars resulted in ITQ-36_30. The diffractogram of this sample is characteristic of the delaminated structure, due to the lack of the basal reflections typical of the pillared samples with the parallel ordering of the zeolite layers. The (200) diffraction peak at about $9.3^{\circ}$ is only slightly shifted in relation to the (200) reflection in the diffractogram of FER_30 $\left(9.7^{\circ}\right)$, indicating the presence of small micropores, with a diameter of about $0.5 \mathrm{~nm}$ located in the interlayer space of the zeolite. However, the very low intensity of this reflection, in comparison to the (200) reflection recorded for FER_30, shows only a small contribution of this fraction of material in the ITQ-36_30 sample. The comparison of diffractograms recorded for FER_30 and FER_50, with respect to the intensity of the reflections, shows that the calcination of 
PREFER_50 resulted in the ferrierite zeolite with better crystallinity, as shown in Figure 1. However, the disappearance of the (200) reflection in the diffractogram of the swollen PREFER_50 sample indicates the delamination of its layered structure. The very small diffraction peak, in the position characteristic of the (200) reflection, in the diffractogram of PREFER_50 indicates that only a small fraction of this sample was not swollen. Moreover, the swelling process, conducted in strong basic media, resulted in the significant destruction of the zeolite structure, which corresponded to decreased intensity or the disappearance of the reflections characteristic of the intralayer ordering of the zeolite structure. The broad reflection in the range of $15-30^{\circ}$ indicates the presence of amorphous silica [21], which was possibly formed by the extraction of silica from the zeolite precursor in strong basic media used for the swelling of PREFER_50. Possibly part of the dissolved silica was precipitated in a solution and deposited on the external zeolite surface in the form of amorphous silica aggregates. Thus, it seems that the stability of the ferrierite precursors (PREFER) in a basic media strongly depends on the $\mathrm{Si} / \mathrm{Al}$ ratio. The high-silica ferrierite precursors are significantly less stable in basic media than the low-silica PREFER samples. The delamination and intercalation of the swollen PREFER_50 sample resulted in delaminated materials, consisting of chaotically organized defected zeolite layers with a significant contribution of amorphous silica. The low intensive (200) reflection at $9.7^{\circ}$ indicates the presence of a ferrierite phase in these samples.

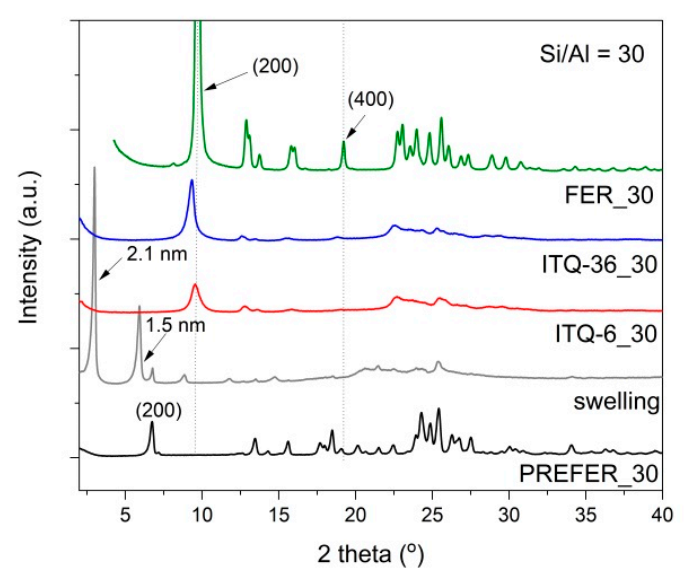

(a)

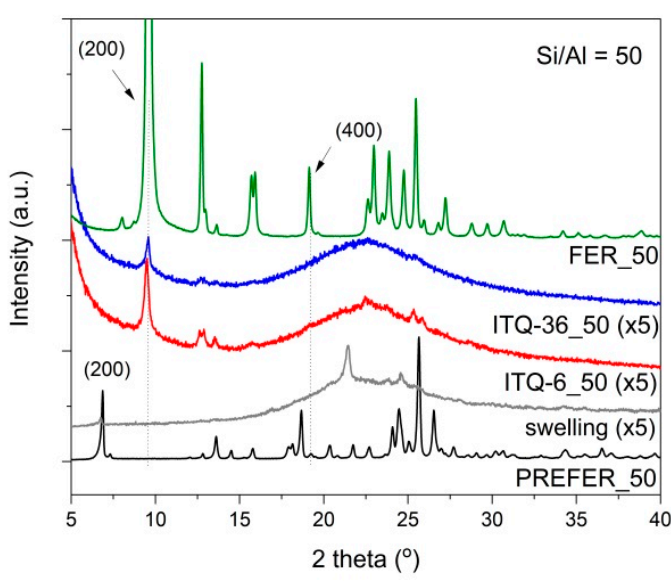

(b)

Figure 1. X-ray diffraction patterns of ferrierite zeolite-based samples (PREFER, swelled PREFER, delaminated ITQ-6, pillared ITQ-36, FER) with Si/Al molar ratios of 30 (a) and 50 (b).

The dinitrogen adsorption-desorption isotherms of the studied samples are presented in Figure 2, while their textural parameters are compared in Table 1. The isotherms of FER_30 and FER_50 are type I, according to the IUPAC classification [22], characteristic of microporous materials. The microporous character of the samples is indicated by a steep adsorption at low relative pressure, assigned to dinitrogen capillary condensation in micropores [23]. The isotherms of the ITQ-6_30 and ITQ-6_50, as well as the ITQ-36_30 and ITQ-36_50 samples, presented in Figure 2, are type IV, according to the IUPAC classification [22], characteristic for mesoporous materials. However, an increase in adsorbed dinitrogen volume, observed at very low relative dinitrogen pressure, also indicates a significant contribution of micropores in these series of the zeolitic samples. Micropores are located in the zeolitic layers, while mesopores are the spaces between intercalated and delaminated zeolite layers in ITQ-36 and ITQ-6, respectively. As it was shown by XRD analysis, the swelling of high-silica PREFER_50 resulted in the partial extraction of silicon from the ferrierite layers with the formation of amorphous silica, identified in ITQ-6_50 and ITQ-36_50, as shown in Figure 1. Thus, an increase in adsorbed dinitrogen volume, observed at higher relative pressure for these samples, indicates not only the presence of interlayer mesopores but also mesopores of different size in amorphous silica [24]. 
The hysteresis loops present in the adsorption-desorption isotherms of ITQ-6_30 and ITQ-36_30 are type $\mathrm{H} 4$, typical for mesoporous zeolites and micro-mesoporous materials, while the hysteresis loops recorded for ITQ-6_50 and ITQ-36_50 are type H3, characteristic of non-rigid aggregates of plate-like particles [22]. The characteristic step down in the desorption isotherms, associated with hysteresis loop observed for ITQ-6_50 and ITQ-36_50, indicates the presence of partially plugged mesopores [25].

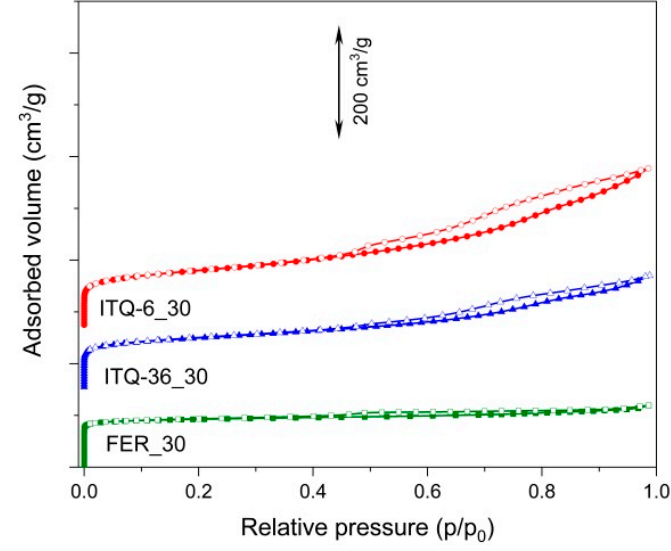

(a)

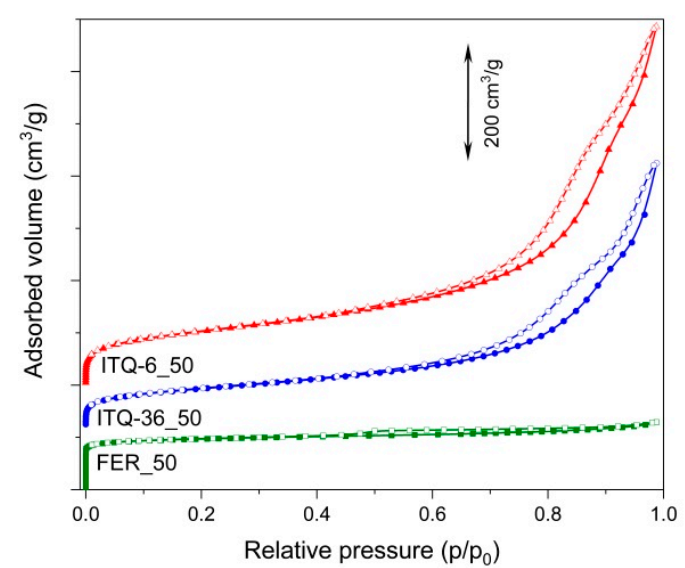

(b)

Figure 2. Nitrogen adsorption-desorption isotherms of the FER, ITQ-6 and ITQ-36 samples with Si/Al molar ratios of $30(\mathbf{a})$ and $50(\mathbf{b})$.

Table 1. Textural and acidic properties of the samples before and after modification with $\mathrm{Cu}$.

\begin{tabular}{ccccccc}
\hline Sample & $\mathbf{S}_{\text {BET }}\left[\mathbf{m}^{2} / \mathbf{g}\right]$ & $\begin{array}{c}\text { Total Pore } \\
\text { Volume } \\
{\left[\mathbf{c m}^{3} / \mathbf{g}\right]}\end{array}$ & $\begin{array}{c}\text { Micropore } \\
\text { Volume } \\
{\left[\mathbf{c m}^{\mathbf{3}} / \mathbf{g}\right]}\end{array}$ & $\begin{array}{c}\text { Mesopore } \\
\text { Volume } \\
{\left[\mathbf{c m}^{3} / \mathbf{g}\right]}\end{array}$ & $\begin{array}{c}\text { Acid Sites Conc. } \\
{[\mu \mathrm{mol} / \mathbf{g}]}\end{array}$ & $\begin{array}{c}\text { Acid Sites Conc. } \\
{\left[\mu \mathrm{mol} / \mathbf{m}^{2}\right]}\end{array}$ \\
\hline FER_30 & 376 & 0.18 & 0.13 & 0.08 & 245 & 0.65 \\
FER_50 & 377 & 0.20 & 0.13 & 0.10 & 49 & 0.16 \\
ITQ-6_30 & 394 & 0.48 & 0.07 & 0.46 & 375 & 0.95 \\
ITQ-6_50 & 372 & 1.06 & 0.02 & 1.12 & 37 & 0.10 \\
ITQ-36_30 & 345 & 0.34 & 0.08 & 0.29 & 314 & 0.01 \\
ITQ-36_50 & 265 & 0.78 & 0.02 & 0.82 & 23 & 0.61 \\
Cu-FER_30 & 362 & 0.21 & 0.13 & 0.08 & 220 & 79 \\
Cu-FER_50 & 359 & 0.20 & 0.12 & 0.11 & 497 & 1.65 \\
Cu-ITQ-630 & 302 & 0.28 & 0.07 & 0.22 & 162 & 0.58 \\
Cu-ITQ-6_50 & 281 & 0.50 & 0.02 & 0.47 & 538 & 1.52 \\
Cu-ITQ-36_30 & 355 & 0.40 & 0.05 & 0.35 & 121 & 1.03 \\
Cu-ITQ-36_50 & 215 & 0.71 & 0.02 & 0.69 & & \\
\hline
\end{tabular}

Profiles of pore size distribution in the micropore and mesopore ranges for ferrierites and their delaminated and intercalated forms are shown in Figure 3. In the case of FER_30 and FER_50, the maximum micropore size distribution, located at about $0.53-0.55 \mathrm{~nm}$, fits very well to the diameter of $10 \mathrm{MR}$ (member ring) channels in ferrierite $[16,26]$. In the mesopore range, the only small contribution of pores with the diameter below $15 \mathrm{~nm}$ was found for both ferrierite samples. The delamination and intercalation of PREFER_30, resulting in ITQ-6_30 and ITQ-36_30, respectively, reduced the intensity of micropore size distribution profile, as shown in Figure 3. This effect is related to the ordered microporous structure limited only to the zeolite layers in the case of ITQ-6_30 and ITQ-36_30, and the three dimensional microporous structure of FER_30 and FER_50. In the mesopore range, the maxima of pore size distribution are at about 3.6 and $2.6 \mathrm{~nm}$ for ITQ-6_30 and ITQ-36_30, respectively. For both these samples, the tails up to about $18 \mathrm{~nm}$ indicate the high heterogeneity of pore sizes, which is characteristic of delaminated materials. The microporous character of ITQ-6_50 and ITQ-36_50 is significantly different than the ITQ-6_30 and ITQ-36_30 samples, as shown in Figure 3. The maximum 
characteristic of the ferrierite $10 \mathrm{MR}$ channels disappeared, while broad and low-intensive peaks at about $0.6-0.7 \mathrm{~nm}$ with long tails from the side of larger pores indicate the high heterogeneity of micropore sizes. These results are consistent with the XRD studies, which showed the partial destruction of the ferrierite layers during PREFER_50 swelling. The mesopore size distribution in ITQ-6_50 and ITQ-36_50 is much broader than for the analogous zeolitic samples with the lower $\mathrm{Si} / \mathrm{Al}$ ratio. The maxima are located at about 4.5 and $2.6 \mathrm{~nm}$ for ITQ-6_50 and ITQ-36_50, respectively. It was shown by the XRD analysis of these samples that part of the silicon was extracted from the zeolite layers during PREFER_50 swelling and was then deposited in the form of amorphous silica aggregates on the zeolite external surface, as shown in Figure 1. Thus, possibly the mesopores of various size, present in amorphous silica, contribute in the mesopore size distribution profiles of ITQ-6_50 and ITQ-36_50. The textural parameters of all the studied samples are presented in Table 1. Micropores dominate in FER_30 and FER_50, while in their delaminated and intercalated forms the contribution of micropores is reduced, while the mesopore volume significantly increased. The introduction of copper into these zeolitic samples decreased their textural parameters.

The elemental compositions of the zeolitic samples, presented in Table 2, show that the real Si/Al ratios, determined by the ICP-OES method, are 22 for FER_30 and 64 for FER_50, so slightly different from the intended values of 30 and 50, respectively. The delamination of PRERER_30 did not change the Si/Al ratio in ITQ-6_30. However, in the case of ITQ-6_50, the Si/Al ratio increased to 214, indicating a decrease in aluminum content in this sample. As previously discussed, the swelling conducted in strong basic conditions resulted in the partial leaching of silicon from the zeolite layers of PREFER_50, which in solution possibly formed amorphous silica aggregates deposited on the zeolite surface. This effect was observed only for high-silica zeolite, which is possibly less stable in basic conditions. In the next step of ITQ-6_50 synthesis, the swollen PREFER_50 was treated in acidic conditions, which possibly resulted in the effective leaching of aluminum from the partially degraded zeolite layers. Additionally, the partial dealumination of PREFER_50 in swelling conditions, as the process assisting silicon leaching, cannot be excluded. The intercalation of the zeolite precursors with silica to obtain ITQ-36_30 and ITQ-36_50 resulted in an increase in the Si/Al ratio. The content of copper introduced to the zeolitic samples is in the range of $0.9-2.7 \mathrm{wt} \%$, as shown in Table 2. Taking into account that one $\mathrm{Al}^{+3}$ cation in the zeolite framework generates one negative charge in such a framework, as well as taking into account that cooper is deposited in the form of $\mathrm{Cu}^{2+}$ cations, the number of copper cations introduced by the ion-exchange mechanism should be two-times lower than the $\mathrm{Al}^{3+}$ cations in the zeolite framework. The $\mathrm{Cu} / \mathrm{Al}$ molar ratio for FER_30 and its delaminated and pillared forms, as well as for FER_50, are in the range of 0.55-0.64, thus it seems that, in these cases, the ion-exchange mechanism dominated in copper deposition. Much larger $\mathrm{Cu} / \mathrm{Al}$ ratios, determined for ITQ-6_50 and ITQ-36_50 indicate a contribution, aside from ion-exchange, also other mechanisms of copper species deposition.

The surface acidity of the zeolitic samples was studied by the temperature-programmed desorption of ammonia ( $\left.\mathrm{NH}_{3}-\mathrm{TPD}\right)$. Ammonia is a basic molecule with respect to both Brønsted and Lewis theory and therefore may interact with both these types of acid sites. Moreover, the diameter of the ammonia molecule is about $0.3 \mathrm{~nm}$ and therefore may easily penetrate all microporous channels in ferrierite $[27,28]$. The ammonia desorption profiles, presented in Figure 4A, consist of two desorption peaks and are characteristic of ferrierite zeolites [26]. The low-temperature maximum was centered at about $205-215{ }^{\circ} \mathrm{C}$ for the samples with the intended Si/Al ratio in the zeolite framework of 30 , and at about $175-195{ }^{\circ} \mathrm{C}$ for the zeolites with the intended framework Si/Al ratio of 50, which indicates the presence of the relatively weak acid sites. The second, much broader and less intensive maxima, centered at about $405-445^{\circ} \mathrm{C}$ for the zeolites with the intended framework Si/Al ratio of 30 and at about $300-405^{\circ} \mathrm{C}$ for the samples with the $\mathrm{Si} / \mathrm{Al}$ ratio in the zeolite framework of 50, are related to the stronger acid sites. The most significant difference in desorption profiles is related to their intensity depending on the $\mathrm{Si} / \mathrm{Al}$ ratio. It is not surprising, assuming that the surface acidity depends on the aluminum content in the zeolitic samples. The deposition of copper into zeolites resulted in a very significant modification of the ammonia desorption profiles, as shown in Figure 4B. In the case of FER_30, 
the intensity of the low-temperature maximum was significantly reduced, while the high-temperate maximum was shifted to lower temperature. The similar effect of the high-temperature maximum shift to lower temperature was observed for FER_50; however, in this case the deposition of cooper resulted in an increase in ammonia adsorption. The ammonia desorption profiles of delaminated and intercalated zeolites consist of one broad and asymmetric maximum, centered at about $245{ }^{\circ} \mathrm{C}$ in the case of the samples with the lower $\mathrm{Si} / \mathrm{Al}$ ratio, while for zeolites with the higher $\mathrm{Si} / \mathrm{Al}$ ratio at a temperature about $15-25^{\circ} \mathrm{C}$ lower. Moreover, the surface concentration of adsorbed ammonia increased after copper deposition to these samples. Thus, the introduction of copper into the zeolitic samples very significantly modified their surface acidic properties. It should not be surprising, taking into account that possibly all ion-exchange positions were substituted by copper species, as shown in Table 2, and in the Cu-ITQ-6_50 and Cu-ITQ-36_50 samples the content of deposited copper is a few times higher than their ion-exchange capacity, as shown in Table 2. Copper species introduced to zeolites play a role in the Lewis acid sites, which can accommodate a free electron pair of ammonia molecules into unoccupied d-orbital. Of course the content of ammonia chemisorbed in this way depends on the surface availability of the copper species and, therefore, their dispersion. The results of $\mathrm{NH}_{3}$-TPD should be discussed not only as an evaluation of the surface acidity of the samples, but also as important steps in the $\mathrm{NH}_{3}$-SCR and AMOx processes, in which chemisorption and the activation of ammonia is one of the main stages $[2,14]$. This topic will be discussed together with the results of the catalytic tests.

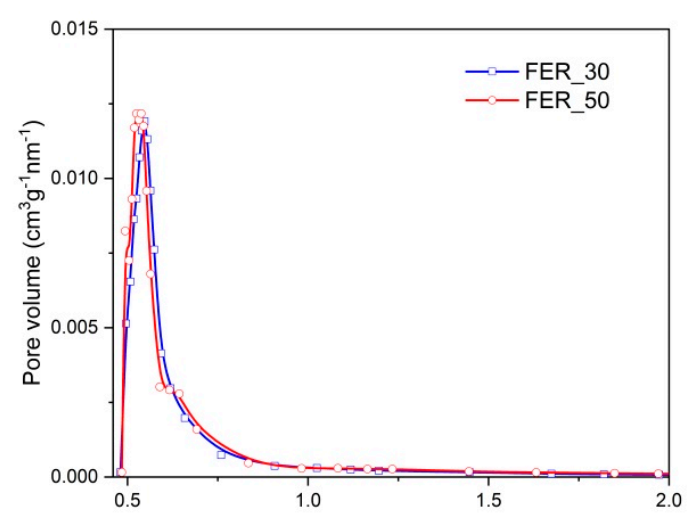

(a)

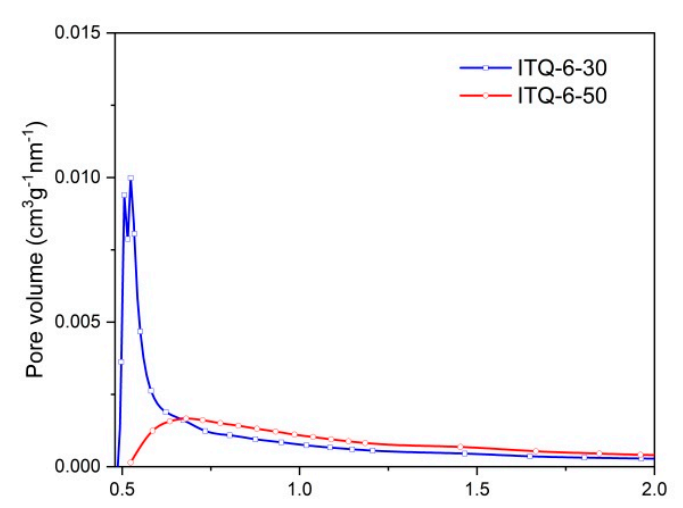

(c)

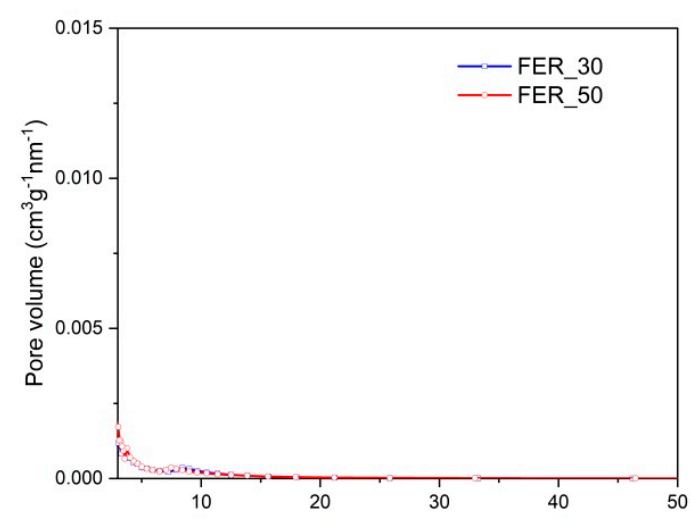

(b)

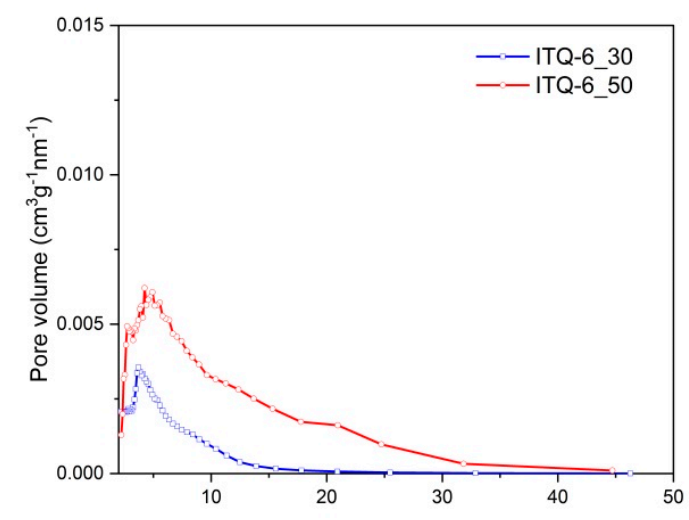

(d)

Figure 3. Cont. 


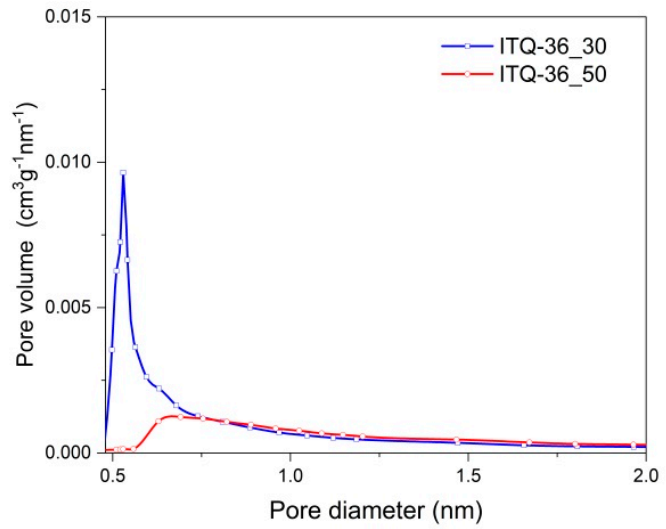

(e)

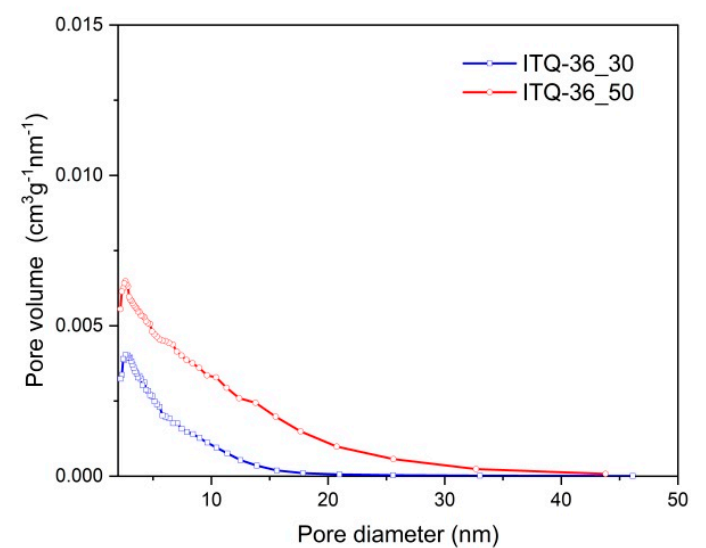

(f)

Figure 3. Pore size distributions of FER, ITQ-6 and ITQ-36 in micropore (left-(a,c,e), respectively) and mesopore range (right- $-(\mathbf{b}, \mathbf{d}, \mathbf{f})$, respectively).

Table 2. Silicon, aluminum and copper contend in FER, ITQ-6 and ITQ-36 samples.

\begin{tabular}{cccccc}
\hline Sample & $\begin{array}{c}\mathbf{S i} \\
\text { [wt \%] }\end{array}$ & $\begin{array}{c}\mathbf{A l} \\
{[\mathbf{w t} \%]}\end{array}$ & $\begin{array}{c}\mathbf{C u} \\
{[\mathbf{w t} \text { \%] }}\end{array}$ & $\begin{array}{c}\text { Si/Al } \\
{[\mathbf{m o l} / \mathbf{m o l}]}\end{array}$ & $\begin{array}{c}\mathbf{C u} / \mathbf{A l} \\
{[\mathbf{m o l} / \mathbf{m o l}]}\end{array}$ \\
\hline FER_30 & 44.9 & 2.0 & - & 22 & - \\
FER_50 & 46.1 & 0.7 & - & 64 & - \\
ITQ-6_30 & 44.9 & 2.0 & - & 22 & - \\
ITQ-6_50 & 46.7 & 0.2 & - & 214 & - \\
ITQ-36_30 & 45.0 & 1.9 & - & 23 & - \\
ITQ-36_50 & 46.5 & 0.2 & - & 224 & - \\
Cu-FER_30 & 43.4 & 2.0 & 2.6 & 21 & 0.55 \\
Cu-FER_50 & 45.6 & 0.6 & 0.9 & 73 & 0.64 \\
Cu-ITQ-6_30 & 43.4 & 1.9 & 2.7 & 22 & 0.60 \\
Cu-ITQ-6_50 & 44.9 & 0.2 & 2.7 & 216 & 5.74 \\
Cu-ITQ-36_30 & 45.1 & 1.8 & 2.5 & 24 & 0.59 \\
Cu-ITQ-36_50 & 46.5 & 0.2 & 2.7 & 224 & 5.20 \\
\hline
\end{tabular}

The analysis of the pyridine pre-adsorbed samples by FTIR spectroscopy, which is a standard method used for determination of Brønsted and Lewis acid site contribution, is very problematic in the studies of the ferrierite based samples. According to Wichterlova et al. [29] and Starzyk et al. [30], the kinetic diameter of pyridine is about $0.57 \mathrm{~nm}$, which is bigger than the diameter of $10 \mathrm{MR}$ channels in ferrierite $[16,26]$, and therefore cannot be used for the analysis of acid sites located inside such channels.

The coordination and aggregation of copper species introduced into the zeolitic samples was studied by UV-vis-DR spectroscopy, as shown in Figure 5. The intensive band centered at about $220-245 \mathrm{~nm}$, present in the spectra of all copper-containing samples, is related to monomeric $\mathrm{Cu}^{2+}$ ions interacting with the oxygen of the zeolite framework $\left(\mathrm{O}^{2-} \rightarrow \mathrm{Cu}^{2+}\right)$ [31-33]. In the case of Cu-FER_30, the band centered at $340 \mathrm{~nm}$ indicates the presence of small oligomeric copper oxide species [31-33]. Additionally, the shoulders in the range of $280-400 \mathrm{~nm}$, observed in the spectra of other samples, are attributed to such small copper oxide aggregates. Moreover, the shoulder above $400 \mathrm{~nm}$ could be assigned to the presence of small $\mathrm{CuO}$ crystallites [31]. Copper oxide crystallites were not identified by XRD analysis of the samples, which indicates that their size is below the detection level of this experimental method. For the samples of the Cu-ITQ-6 and Cu-ITQ-36 series, the bands above $600 \mathrm{~nm}$ are assigned to the $\mathrm{d}-\mathrm{d}$ transition of $\mathrm{Cu}^{2+}$ ions in pseudo-octahedral coordination (e.g., $\left.\mathrm{Cu}\left(\mathrm{H}_{2} \mathrm{O}\right)_{6}{ }^{2+}\right)$ [31-33], and therefore indicate, similarly to the bands at $220-245 \mathrm{~nm}$, the significant contribution of copper deposited in the form of monomeric cations. 

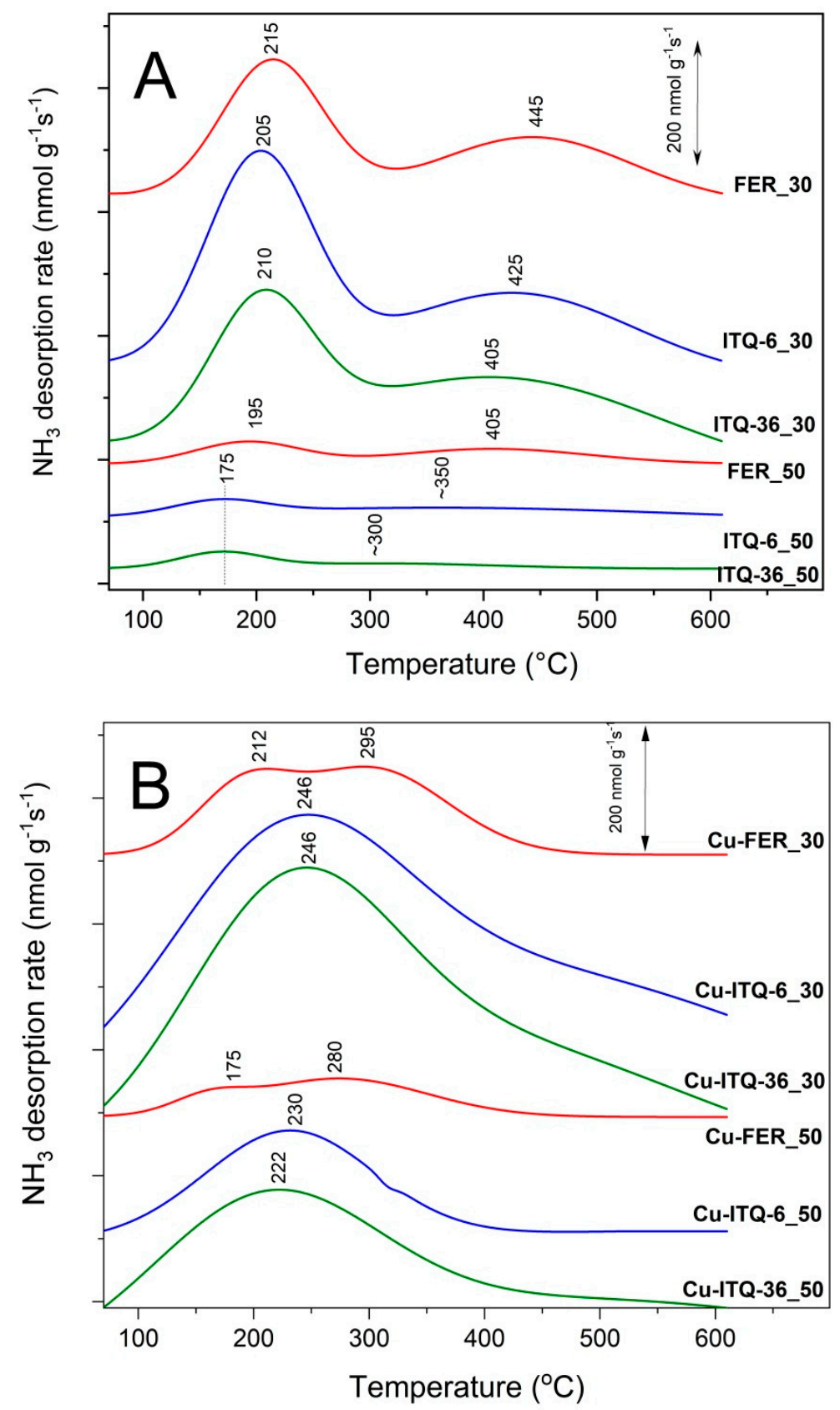

Figure 4. $\mathrm{NH}_{3}$-TPD profiles of FER, ITQ-6 and ITQ-36 zeolites (A) and their modifications with copper (B).

The $\mathrm{H}_{2}$-TPR profiles of the zeolitic samples modified with copper are shown in Figure 6 . The reduction profiles of copper species depend on their form and aggregation. In the case of $\mathrm{Cu}^{2+}$ cations in $\mathrm{CuO}$ crystallites or bulky oligomeric crystallites their reduction directly precedes to $\mathrm{Cu}^{0}$ in the temperature range of $200-300{ }^{\circ} \mathrm{C}[1,6]$. The reduction of monomeric $\mathrm{Cu}^{2+}$ cations includes the reduction of $\mathrm{Cu}^{2+}$ to $\mathrm{Cu}^{+}$at temperatures below $300{ }^{\circ} \mathrm{C}$ and, at higher temperatures, the reduction of monomeric $\mathrm{Cu}^{+}$to $\mathrm{Cu}^{0}[1,6]$. Thus, the $\mathrm{H}_{2}$-TPR studies are very informative with respect to the determination of the types of copper species introduced into the zeolitic samples. The reduction profiles of Cu-FER_30 and Cu-FER_50 contain intensive double peaks at temperatures below $300{ }^{\circ} \mathrm{C}$ with the only low intensive and broad peaks at higher temperatures, which indicate the presence of copper mainly in the form of aggregated species with the small contribution of monomeric copper cations, as shown in Figure 6. The reduction profiles of Cu-ITQ-6_30 and Cu-ITQ-6_50 are spread up to temperatures of $650-700{ }^{\circ} \mathrm{C}$ and contain at least three unresolved maxima. The low-temperature 
maxima, centered at about $235-245{ }^{\circ} \mathrm{C}$, as mentioned earlier, could be attributed to the direct reduction of $\mathrm{CuO}$ to metallic copper and the reduction of monomeric $\mathrm{Cu}^{2+}$ cations to $\mathrm{Cu}^{+}$. However, the intensive high-temperature maxima, centered at about $475-505{ }^{\circ} \mathrm{C}$ and related to the reduction of isolated $\mathrm{Cu}^{+}$to $\mathrm{Cu}^{0}$, may indicate the presence of mainly highly dispersed copper species in these samples. The peak at about $370{ }^{\circ} \mathrm{C}$ in the reduction profile of Cu-ITQ-6_30 and the arm at a similar temperature in the profile of Cu-ITQ-6_50 are possibly attributed to the reduction of finely dispersed $\mathrm{CuO}$ particles to elemental $\mathrm{Cu}^{0}[34,35]$. The maxima in the reduction profile of the sample with the higher Si/Al ratio, Cu-ITQ-6_50, are shifted to higher temperatures, compared to $\mathrm{Cu}-\mathrm{ITQ}-6 \_30$. A similar effect was reported in the scientific literature and was explained by the lower electronic density of the samples with lower aluminum content, which makes the reduction of the deposited metal species more difficult [36,37]. In the case of $\mathrm{Cu}-\mathrm{ITQ}-36 \_30$ and $\mathrm{Cu}$-ITQ-36_50, the reduction profiles contained low-temperature peaks, centered at about $230-245^{\circ} \mathrm{C}$, and high-temperature maxima at about $445-470{ }^{\circ} \mathrm{C}$, as shown in Figure 6. The intensities of the high temperature peaks are significantly higher compared to the low-temperature ones, which indicates not only the significant contribution of highly dispersed copper species, but also the presence of $\mathrm{Cu}^{+}$cations in these samples. It is possible that part of the highly dispersed copper species was thermally reduced from $\mathrm{Cu}^{2+}$ to $\mathrm{Cu}^{+}$during the treatment of the samples in a flow of pure argon at $500{ }^{\circ} \mathrm{C}$, prior to the $\mathrm{H}_{2}$-TPR runs. A similar effect was reported and analyzed for the Cu-ZSM-5 samples by Yang et al. [38]. This effect may indicate a very high lability in $\mathrm{Cu}^{2+} \rightarrow$ $\mathrm{Cu}^{+}$reduction.

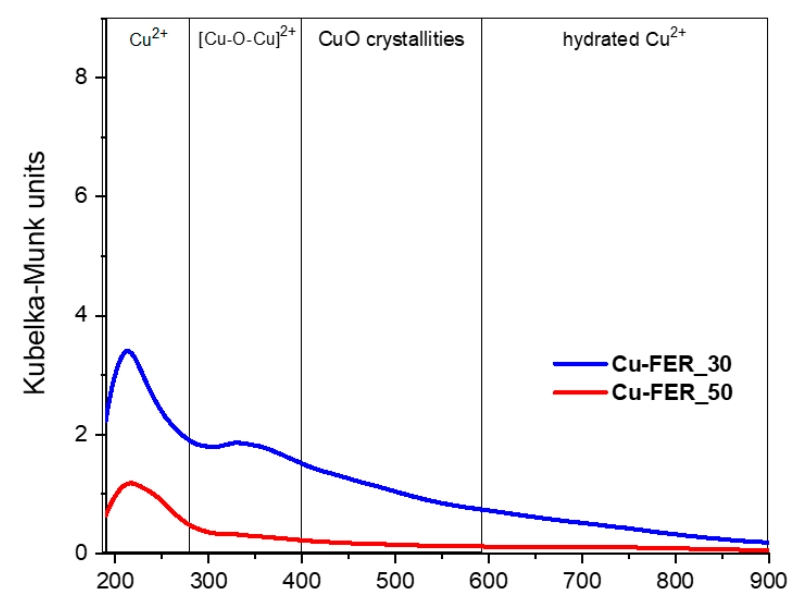

(a)

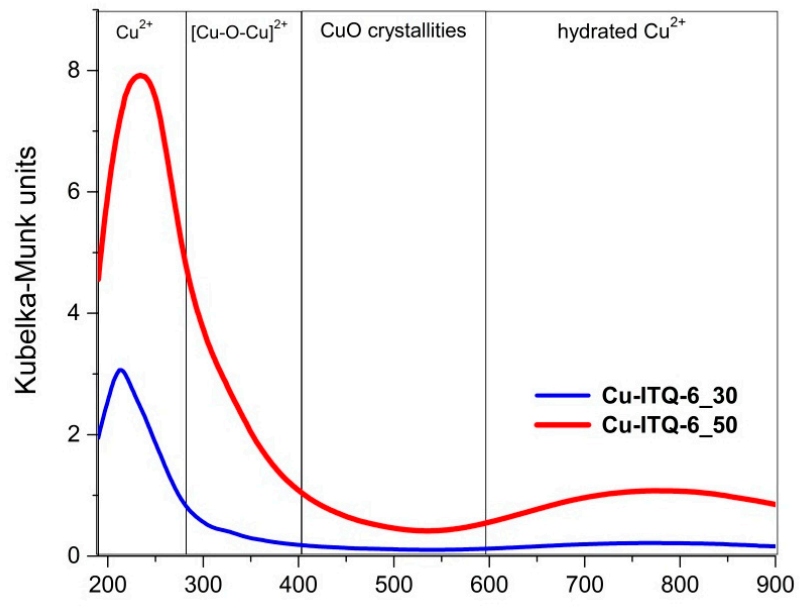

(b)

Figure 5. Cont. 


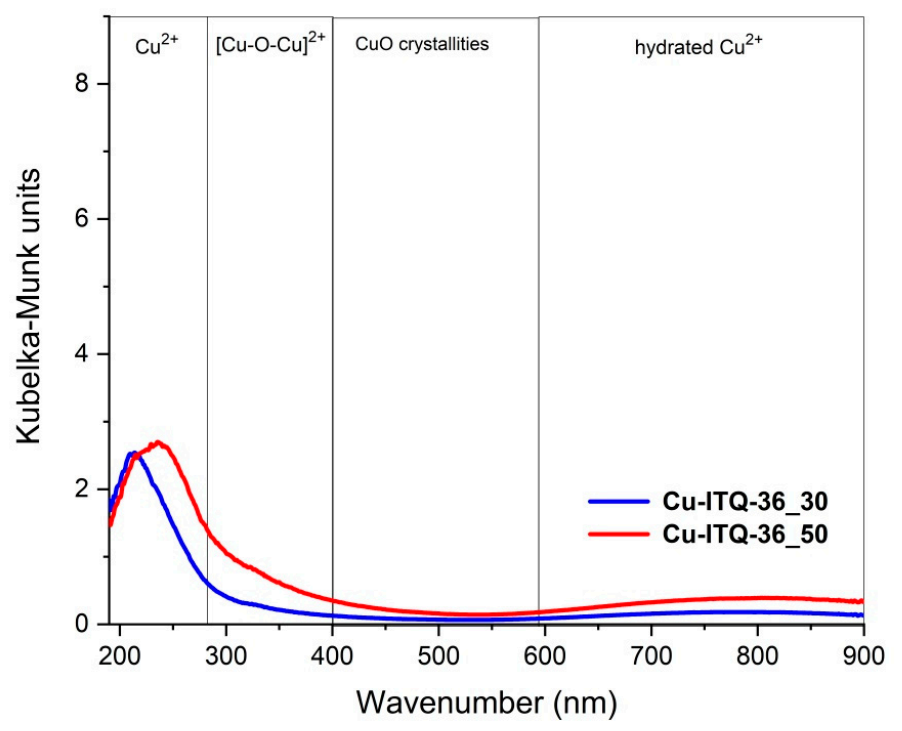

(c)

Figure 5. UV-vis_DR spectra of FER (a), ITQ-6 (b) and ITQ-36 (c) samples modified with Cu.

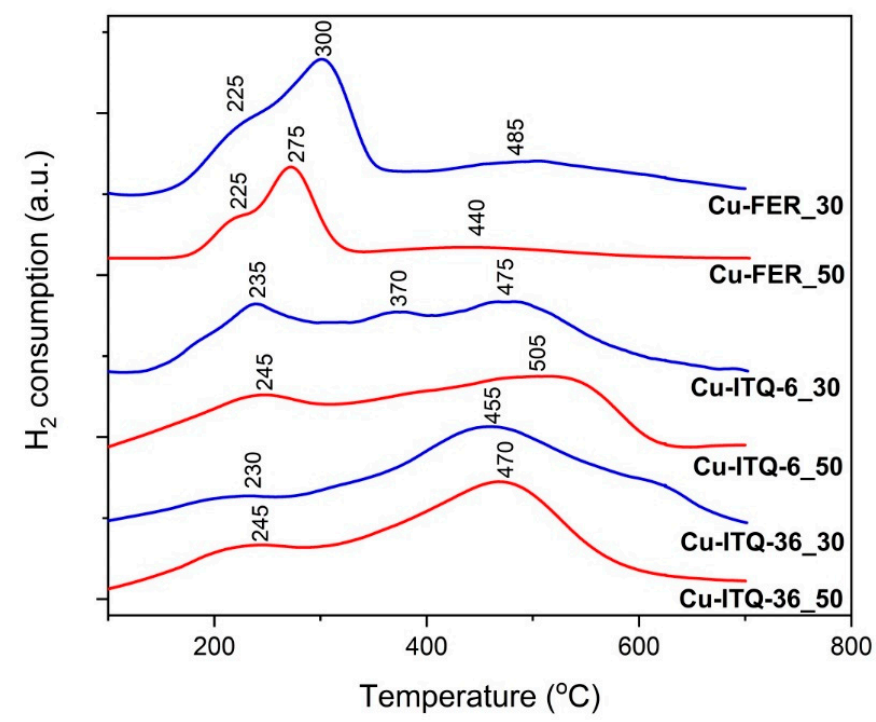

Figure 6. $\mathrm{H}_{2-}$-TPR profiles of FER, ITQ-6 and ITQ-36 samples modified with $\mathrm{Cu}$.

\subsection{Catalytic Studies of $\mathrm{NH}_{3}-\mathrm{SCR}$}

The results of the catalytic tests of copper modified zeolites in the $\mathrm{NH}_{3}-\mathrm{SCR}$ process are presented in Figure 7. The NO conversion in the presence of ferrierite-based catalysts started at about $150-175^{\circ} \mathrm{C}$ and increased to about $375-400{ }^{\circ} \mathrm{C}$, reaching 99 and $86 \%$ for Cu-FER_30 and Cu-FER_50, respectively. The decrease in the NO conversion, observed at higher temperatures, is related to the side reaction of ammonia oxidation by oxygen present in the reaction mixture. The selectivity to dinitrogen, also in the range characteristics of ammonia oxidation, was very high and did not drop below 97\%. Intercalated and delaminated ferrierite zeolites were found to be significantly more catalytically active in the $\mathrm{NH}_{3}-\mathrm{SCR}$ process. First of all, the NO conversion in the presence of the Cu-ITQ-6 catalysts started at about $125{ }^{\circ} \mathrm{C}$ - so at a temperature lower by about $25-50{ }^{\circ} \mathrm{C}$ than in the case of FER based catalysts-and then intensively increased to $275{ }^{\circ} \mathrm{C}$, reaching about 97 and $95 \%$ for Cu-ITQ-6_30 and Cu-ITQ-6_50, respectively. Thus, in the low-temperature range the NO conversion profiles for both catalysts of this series are very similar, indicating the limited role of their surface acidity and copper loading. It can be seen that the catalyst with the higher aluminum content, Cu-ITQ-6_30, was more 
catalytically active at temperatures below $150^{\circ} \mathrm{C}$. As it was shown, the reduction of copper species in the zeolitic catalysts with the higher content of framework aluminum occurs at lower temperatures than for zeolites with the lower aluminum content, as shown in Figure 6. Thus, the increased catalytic activity in the low-temperatures range is possibly attributed to the better reducibility of copper species deposited into zeolites. The catalytic performance of these samples is significantly different at higher temperatures. In the presence of Cu-ITQ-6_30, the NO conversion on the level 97-100\% was observed in the range of $275-400{ }^{\circ} \mathrm{C}$, while for Cu-ITQ-6_50 a decrease in the NO conversion, due to the side reaction of ammonia oxidation, occurred at about $325^{\circ} \mathrm{C}$. The selectivity to dinitrogen is higher for Cu-ITQ-6_30. Thus, the sample with the higher surface acidity, Cu-ITQ-6_30, is a more effective catalyst in the high-temperature $\mathrm{NH}_{3}-\mathrm{SCR}$ process. Similar results were obtained for the series of the Cu-ITQ-36 samples. The catalyst with the higher aluminum content, Cu-ITQ-36_30, presented better catalytic activity at temperatures below $175^{\circ} \mathrm{C}$, possibly due to the better reducibility of copper species deposited into this sample compared to the copper species in the catalysts with the lower aluminum content, Cu-ITQ-36_50, as shown in Figure 6. The NO conversion in the presence of Cu-ITQ-36_30 increased to about $400^{\circ} \mathrm{C}$, reaching $97 \%$, while in the case of Cu-ITQ-6_50, the NO conversion increased to $93 \%$ at $300{ }^{\circ} \mathrm{C}$ and then decreased due to the side reaction of ammonia oxidation, as shown in Figure 7. Thus, in this case, the acid properties of the catalysts also play a very important role in the high-temperature $\mathrm{NH}_{3}$-SCR process. The comparison of the results, presented in Figure 7 , shows that the catalysts based on ITQ-6 are more active and selective than the analogous catalysts of the ITQ-36 series. On the other hand, the comparison of the results obtained for the FER series and their intercalated and delaminated forms shows that the most significant differences are related to the lower NO conversion for Cu-FER_30 and Cu-FER_50 in the low-temperature range, compared to the catalysts of the Cu-ITQ-6 and Cu-ITQ-36 series. The results of UV-vis DRS, as shown in Figure 5, and $\mathrm{H}_{2}$-TPR, as shown in Figure 6, show a significantly higher contribution of highly dispersed copper species, mainly monomeric copper cations, in the catalysts of the Cu-ITQ-6 and Cu-ITQ-36 series, while the presence of more aggregated copper oxide species was postulated for the samples of the Cu-FER series. Such highly dispersed copper species, which can be reduced at relatively low temperatures, are possibly needed for the low-temperature conversion of NO. One of the possible mechanisms of the low-temperature $\mathrm{NH}_{3}$-SCR is based on fast-SCR $\left(2 \mathrm{NH}_{3}+\mathrm{NO}+\mathrm{NO}_{2} \rightarrow 2 \mathrm{~N}_{2}+3 \mathrm{H}_{2} \mathrm{O}\right)$; however, for this reaction $\mathrm{NO}_{2}$ is needed.

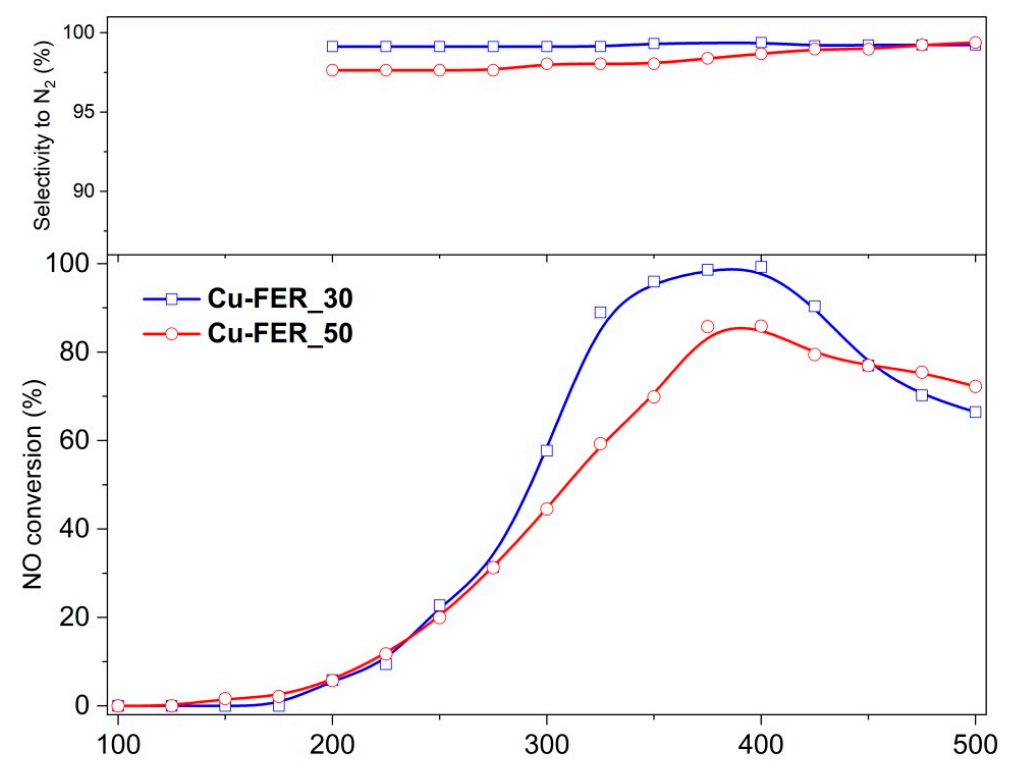

(a)

Figure 7. Cont. 


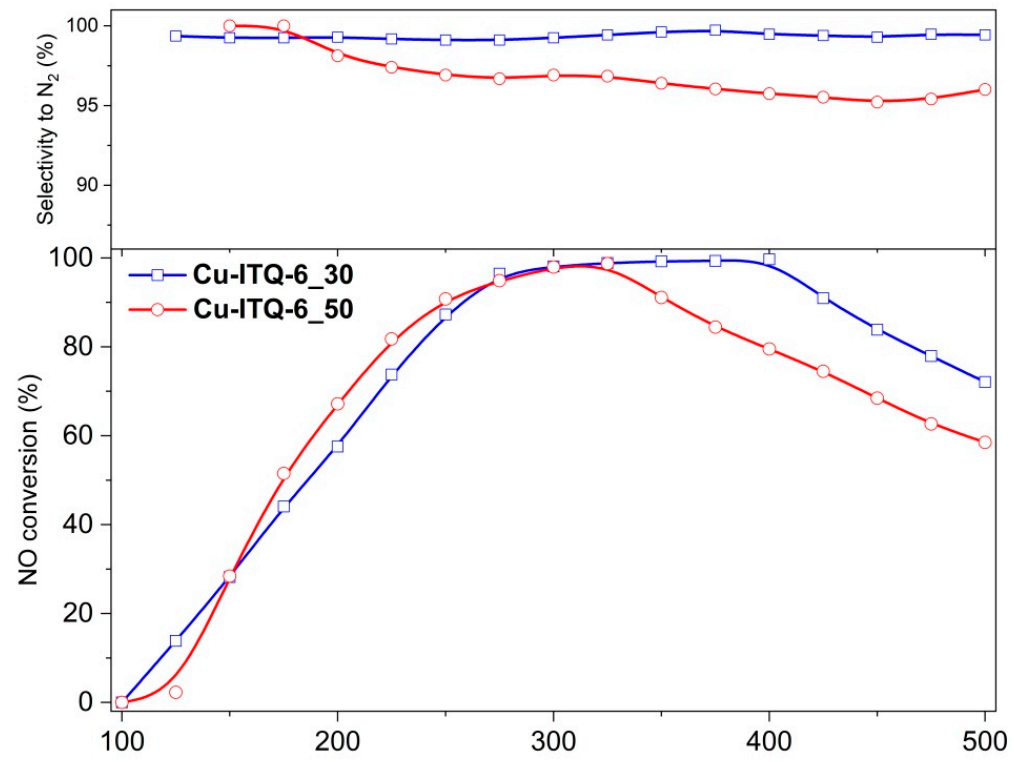

(b)

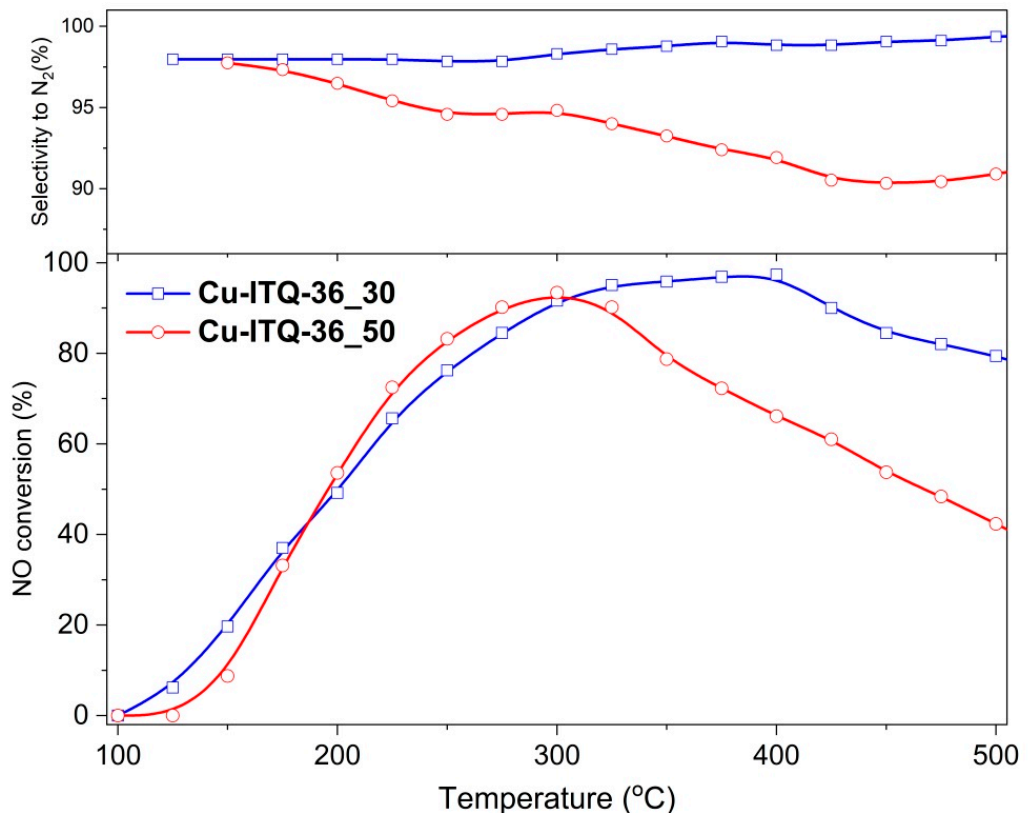

(c)

Figure 7. Results for catalytic $\mathrm{NH}_{3}$-SCR tests for FER (a), ITQ-6 (b) and ITQ-36 (c) samples modified with Cu.

\subsection{Catalytic Studies of $\mathrm{NO}$ to $\mathrm{NO}_{2}$ Oxidation}

The results of the catalytic $\mathrm{NO}$ to $\mathrm{NO}_{2}$ oxidation in the presence of the studied catalysts are presented in Figure 8. The normalized intensity of the FTIR band at $1593 \mathrm{~cm}^{-1}$ was used for the analysis of $\mathrm{NO}_{2}$ formation. It can be seen that the intensity of the band characteristic of $\mathrm{NO}_{2}$ is significantly higher for the $\mathrm{Cu}$-ITQ-6 and Cu-ITQ-36 catalysts than for the $\mathrm{Cu}$-FER samples. Moreover, NO oxidation in the presence of delaminated and intercalated zeolites started at temperatures significantly lower compared to the $\mathrm{Cu}-\mathrm{FER}$ catalysts. The maximal $\mathrm{NO}$ to $\mathrm{NO}_{2}$ conversions, determined from the normalized intensity of the $1912 \mathrm{~cm}^{-1}$ band (characteristic of NO), are about $24 \%$ for the Cu-FER catalysts, $43-45 \%$ for the Cu-ITQ-6 samples and about 33\% for both catalysts of the Cu-ITQ-36 series. Thus, the catalytic activity of the studied zeolitic samples in $\mathrm{NO}$ to $\mathrm{NO}_{2}$ oxidation very well correlates with the activity order of these samples in the low- and middle-temperature $\mathrm{NH}_{3}$-SCR. 


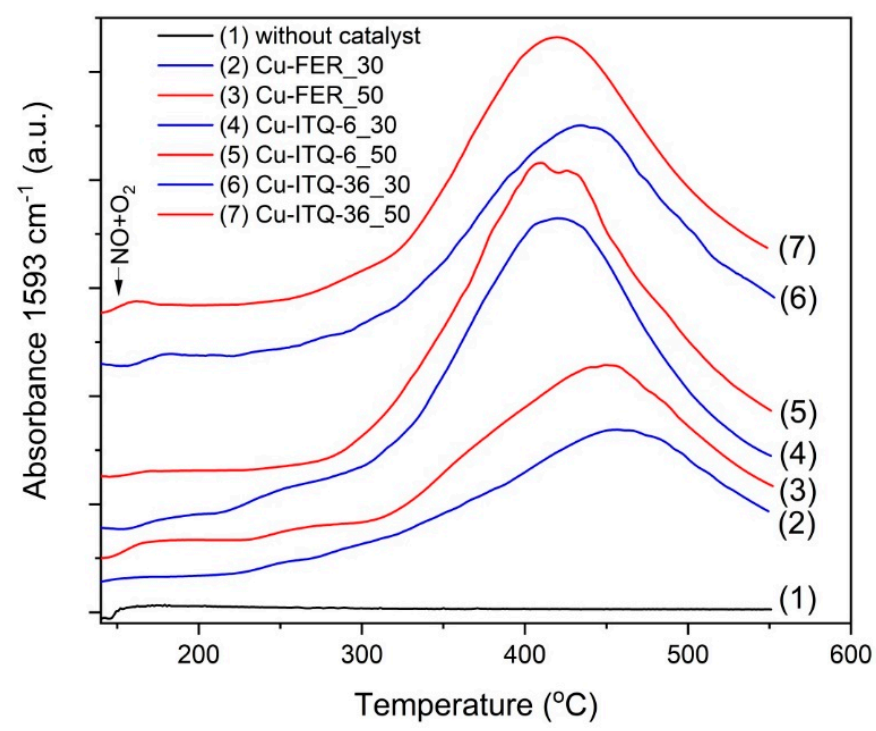

Figure 8. Results of $\mathrm{NO}$ to $\mathrm{NO}_{2}$ oxidation for FER, ITQ-6 and ITQ-36 samples modified with Cu.

\subsection{Catalytic Studies of Ammonia Oxidation (AMOx)}

Analysis of the $\mathrm{NH}_{3}-\mathrm{SCR}$ results, as shown in Figure 7, shows that the high-temperature efficiency of this process is determined by the side reaction of direct ammonia oxidation (AMOx). Catalysts for high-temperature $\mathrm{NH}_{3}$-SCR should be active in $\mathrm{NO}$ reduction with ammonia and simultaneously inactive in ammonia oxidation. The comparison of the $\mathrm{NH}_{3}$-SCR results, obtained for Cu-ITQ-6_30 and Cu-ITQ-36_30, with the results obtained for Cu-ITQ-6_50 and Cu-ITQ-36_50, shows that ammonia oxidation possibly starts at temperature significantly lower for the catalysts with the larger $\mathrm{Si} / \mathrm{Al}$ ratio. On the other side, the results of $\mathrm{NH}_{3}-\mathrm{TPD}$, as shown in Figure 4, show that ammonia is more effectively chemisorbed on the surface of Cu-ITQ-6_30 and Cu-ITQ-36_30 than on Cu-ITQ-6_50 and $\mathrm{Cu}$-ITQ-36_50, which indicates that ammonia coordinated on copper species is effectively activated for the $\mathrm{NH}_{3}-\mathrm{SCR}$ and not activated for direct oxidation. In order to verify the activity of the studied catalysts in the side reaction of ammonia oxidation, which limits the efficiency of the $\mathrm{NH}_{3}-\mathrm{SCR}$ process at higher temperatures, catalytic tests of ammonia oxidation were performed, as shown in Figure 9. The ammonia oxidation in the presence of the catalysts of the Cu-FER series started at about $300{ }^{\circ} \mathrm{C}$ and increased to the level of 80-90\%. Cu-FER_30 presented higher activity and selectivity to dinitrogen than Cu-FER_50. More significant differences in the results of ammonia oxidation were found for the catalysts of the $\mathrm{Cu}$-ITQ-6 and Cu-ITQ-36 series. The ammonia conversion in the presence of the zeolitic catalysts with the higher Si/Al ratio, Cu-ITQ-6_50 and Cu-ITQ-36_50, started at lower temperatures compared to the samples with the lower Si/Al ratio, Cu-ITQ-6_30 and Cu-ITQ-36_30, which is in full agreement with the results of the $\mathrm{NH}_{3}-\mathrm{SCR}$ tests, as shown in Figure 7. Thus, it is supposed that stronger acid sites in the delaminated (Cu-ITQ-6) and intercalated (Cu-ITQ-36) zeolitic samples decrease their activity in ammonia oxidation and, therefore, extend the temperature window of the effective $\mathrm{NH}_{3}$-SCR process to higher temperatures. Another important issue is a very high selectivity of ammonia oxidation to dinitrogen, as shown in Figure 9, which explains the high selectivity towards dinitrogen in the $\mathrm{NH}_{3}-\mathrm{SCR}$ process, and also in the temperature range characteristic of the side reaction of direct ammonia oxidation, as shown in Figure 7. 


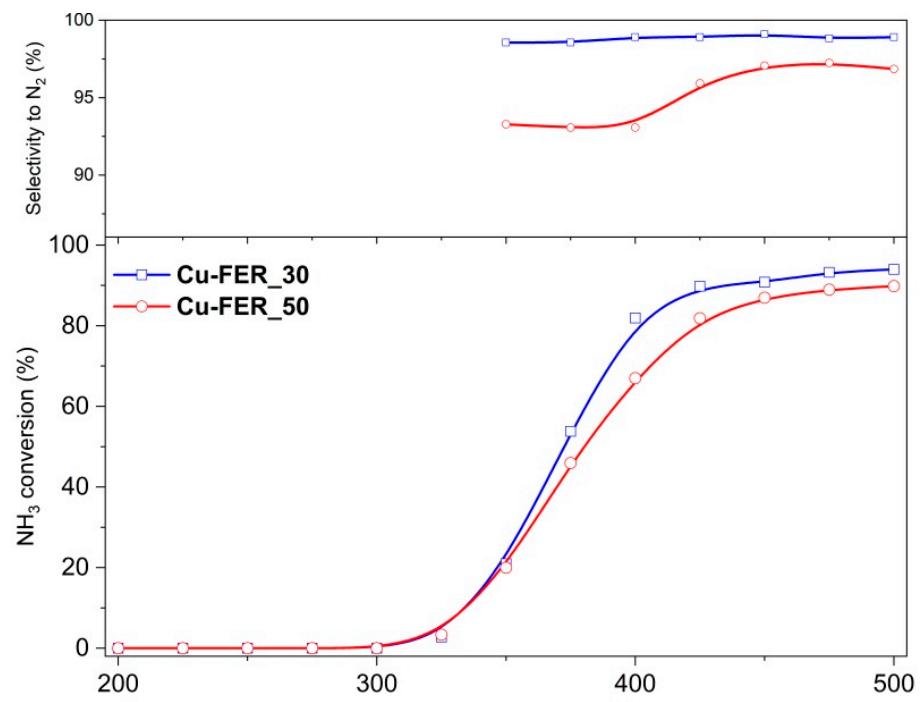

(a)

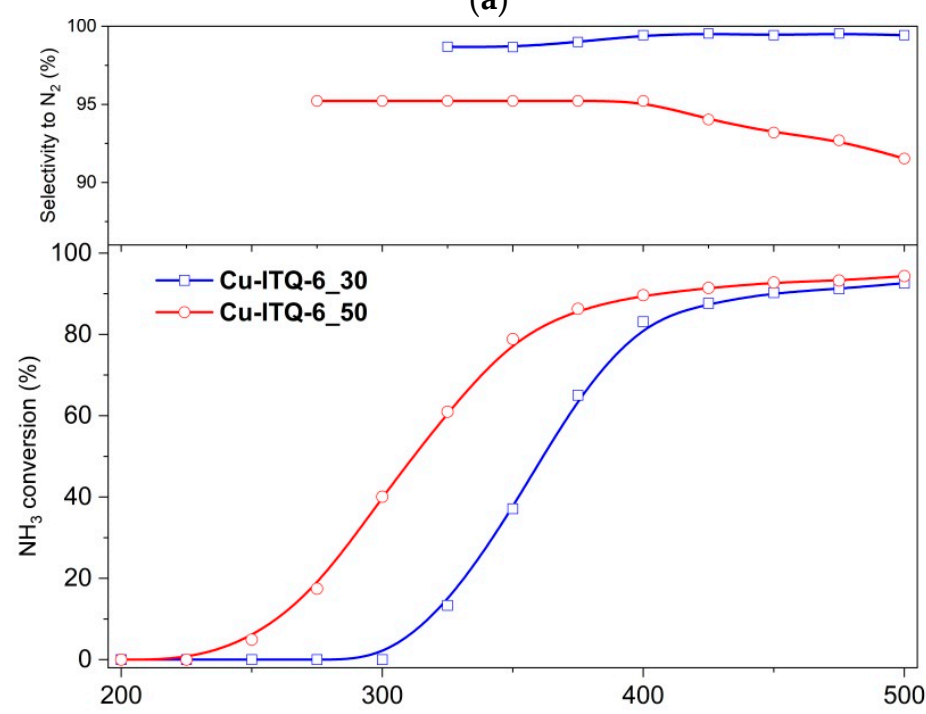

(b)

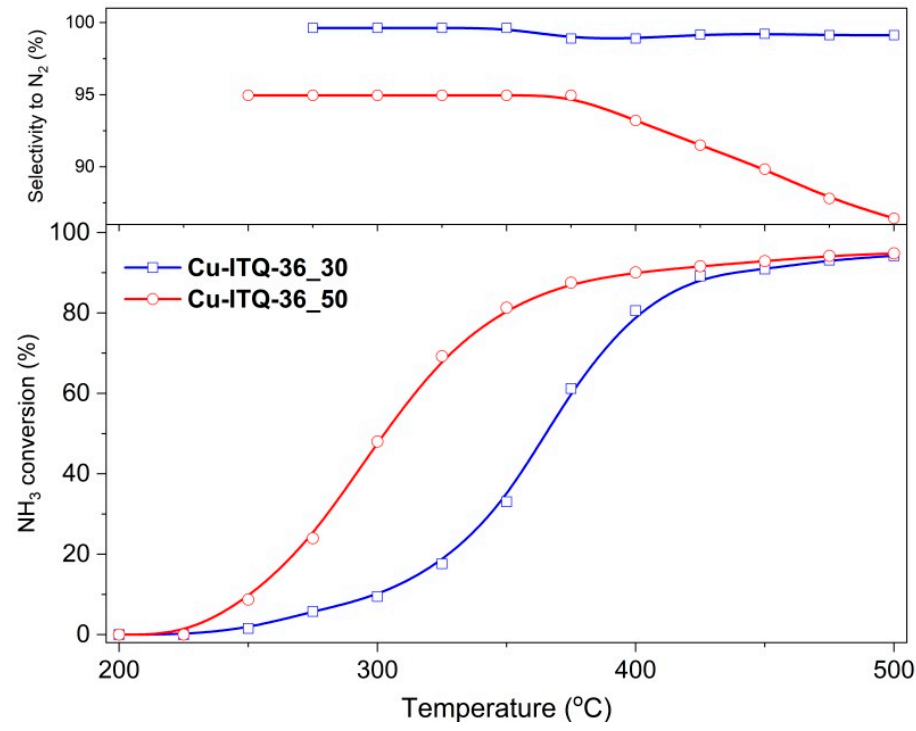

(c)

Figure 9. Results of AMOx tests for FER (a), ITQ-6 (b) and ITQ-36 (c) samples modified with Cu. 
For the most promising catalyst, Cu-ITQ-6_30, selected on the basis of the catalytic tests of the $\mathrm{NH}_{3}$-SCR reaction, as shown in Figure 7, the stability test in $\mathrm{NH}_{3}-\mathrm{SCR}$ was done at $275{ }^{\circ} \mathrm{C}$ for $15 \mathrm{~h}$, as shown in Figure 10. The NO conversion changed in the range of $92.5-94 \%$, while selectivity towards dinitrogen was in the range of 96-99\%. Thus, the Cu-ITQ-6_30 presented high catalytic stability in the $\mathrm{NH}_{3}$-SCR reaction.

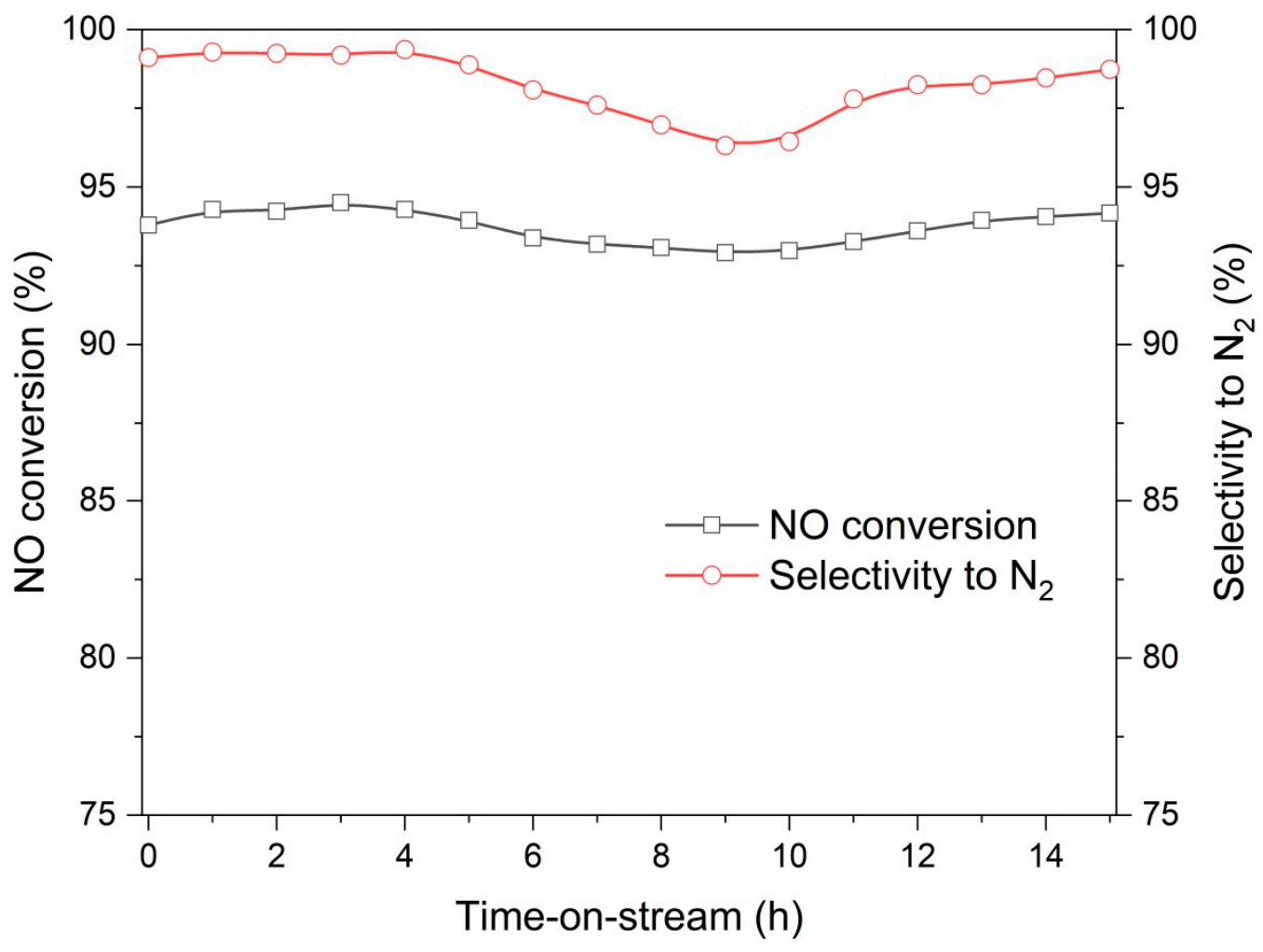

Figure 10. Results of stability $\mathrm{NH}_{3}-\mathrm{SCR}$ test for $\mathrm{Cu}-\mathrm{ITQ}-6 \_30$ at $275^{\circ} \mathrm{C}$.

\section{Experimental}

\subsection{Catalysts Preparation}

\subsubsection{Synthesis of PREFER and FER}

Zeolite precursor materials, PREFER, with different intended Si/Al molar ratios, were prepared using fumed silica Aerosil 200 (Evonik Industries AG, Essen, Germany) as a silicon source, hydroxy(oxo)alumane Catapal B (Sasol, Johannesburg, South Africa) as an aluminum source, 4-amino-2,2,6,6-tetramethylpiperidine ( $R$, Fluka, Germany) as a structure directing agent, $\mathrm{NH}_{4} \mathrm{~F}$ (98\%, Sigma-Aldrich, St. Louis, MO, USA), HF (49.8\%, Sigma-Aldrich, St. Louis, MO, USA) and distillated water in the molar ratios of $1 \mathrm{SiO}_{2}: x \mathrm{Al}_{2} \mathrm{O}_{3}: 1 \mathrm{R}: 1.5 \mathrm{NH}_{4} \mathrm{~F}: 0.5 \mathrm{HF}: 10 \mathrm{H}_{2} \mathrm{O}$, where $\mathrm{x}=0.015$ and 0.01 for the $\mathrm{Si} / \mathrm{Al}$ molar ratios of 30 and 50 , respectively. The obtained gels were mixed in an autoclave at $135^{\circ} \mathrm{C}$ for 3 days. The resulting products were filtered, washed with distillated water and dried overnight at $60^{\circ} \mathrm{C}$. Three dimensional (3D) ferrierite zeolites (FER) were obtained by the calcination of PREFER at $600{ }^{\circ} \mathrm{C}$ for $6 \mathrm{~h}$. The FER zeolites with the intended Si/Al molar ratios of 30 and 50 are denoted as FER_30 and FER_50, respectively.

\subsubsection{PREFER Swelling}

For the swelling of PREFER, an aqueous solution of hexadecyltrimethylammonium bromide (CTMABr, $\geq 99 \%$, Acros Organics, Geel, Belgium) and tetrapropylammonium bromide (TPABr, 98\% Sigma-Aldrich, St. Louis, MO, USA) were used. The solution was prepared by dissolving 
$25 \mathrm{~g} \mathrm{CTMABr} / \mathrm{OH}$ (CTMABr with 50\% $\mathrm{Br}^{-}$ions exchanged for $\mathrm{OH}^{-}$anions) and $12 \mathrm{~g}$ TPABr/OH (TPABr with $30 \% \mathrm{Br}^{-}$ions exchanged for $\mathrm{OH}^{-}$anions) in $113 \mathrm{~g}$ distillated water. The PREFER sample of $5 \mathrm{~g}$ was dispersed in this solution and obtained slurry and was stirred under reflux at $95^{\circ} \mathrm{C}$ for $16 \mathrm{~h}$.

\subsubsection{Synthesis of ITQ-6}

First part of the slurry, containing swelled PREFER, was sonicated in an ultrasound bath $(50 \mathrm{~W}, 40 \mathrm{kHz}$ ) for $1 \mathrm{~h}$. Then, the mixture was acidified to $\mathrm{pH}=3.0$ with concentrated $\mathrm{HCl}$ (high purity grade, Honeywell, Charlotte, NC, USA), separated by centrifugation (12,000 rpm, $20 \mathrm{~min}$ ) and washed with distillated water. Finally, the solid product was calcined at $600{ }^{\circ} \mathrm{C}$ for $6 \mathrm{~h}$, resulting in delaminated ITQ-6 zeolite. The ITQ-6 zeolites with the intended Si/Al molar ratios of 30 and 50 are denoted as ITQ-6_30 and ITQ-6_50, respectively.

\subsubsection{Synthesis of ITQ-36}

The second part of the slurry, containing swelled PREFER, was mixed with tetraethyl orthosilicate (TEOS, $\geq 99 \%$, Merck KGaA, Darmstadt, Germany), used as a pillaring agent, with a swollen PREFER:TEOS weight ratio of 1:5. The obtained mixture was intensively stirred at $90{ }^{\circ} \mathrm{C}$ for $16 \mathrm{~h}$ in dinitrogen atmosphere. Then, the solid product was separated by filtration, washed with ethanol and dried overnight at $60^{\circ} \mathrm{C}$. In the next step, solid material was hydrolyzed by its dispersing in distillated water in the weight ratio of 1:10. The obtained slurry was kept at $100^{\circ} \mathrm{C}$ for $10 \mathrm{~h}$, then the solid product was separated by filtration, washed with distillated water, dried overnight at $60^{\circ} \mathrm{C}$ and finally calcined at $600{ }^{\circ} \mathrm{C}$ for $6 \mathrm{~h}$, resulting in ITQ-36 zeolite. The ITQ-36 zeolites with the intended Si/Al molar ratios of the zeolite layers of 30 and 50 are denoted as ITQ-36_30 and ITQ-36_50, respectively.

\subsubsection{Modification of the Zeolitic Samples with Copper}

The obtained samples of the FER, ITQ-6 and ITQ-36 series were modified with copper by ion-exchange method. The zeolitic samples were dispersed in $0.06 \mathrm{M}$ aqueous solution of $\mathrm{Cu}\left(\mathrm{CH}_{3} \mathrm{COO}\right)_{2} \cdot \mathrm{H}_{2} \mathrm{O}$ with a zeolite:liquid ratio of $10 \mathrm{~g} / 1000 \mathrm{~g}$. The obtained slurry was stirred at $80{ }^{\circ} \mathrm{C}$ for $6 \mathrm{~h}$, then the solid sample was separated by filtration, washed with distillated water, dried overnight at $60^{\circ} \mathrm{C}$ and finally calcined at $550{ }^{\circ} \mathrm{C}$ for $8 \mathrm{~h}$. The samples modified with copper are denoted: Cu-FER_30 and Cu-FER_50; Cu-ITQ-6_30 and Cu-ITQ-6_50; Cu-ITQ-36_30 and Cu-ITQ-36_50.

\subsection{Characterization of the Samples}

The textural properties of the samples were determined by $\mathrm{N}_{2}$ sorption at $-196{ }^{\circ} \mathrm{C}$ using the 3 Flex (Micrometrics, Norcross, GA, USA) automated gas adsorption system. Prior to the analysis, the samples were outgassed under a vacuum at $350^{\circ} \mathrm{C}$ for $24 \mathrm{~h}$. The specific surface area was determined using the BET (Braunauer-Emmett-Teller) model. Micropore size distribution was determined using the Horvath-Kawazoe model, while mesopore volume and mesopore area were enumerated using the BJH (Barrett-Joyner-Halenda) model. The micropore volume $\left(\mathrm{at} p / \mathrm{p}_{0}=0.98\right)$ and specific surface area of the micropores were calculated using the $\mathrm{t}$-plot method. The $\mathrm{X}$-ray diffraction patterns of the samples were obtained using a Bruker D2 Phaser diffractometer (Bruker, Billerica, MA, USA). The measurements were performed in the $2 \Theta$ range of $2-40^{\circ}$ with a step of $0.02^{\circ}$ and a counting time of 1 s per step. The chemical compositions of the samples were analyzed by inductively coupled plasma-optical emission spectrometry (ICP-OES) using iCAP 7400 instrument (Thermo Scientific, Waltham, MA, USA). The solid samples were dissolved in a mixture of hydrofluoric (high purity grade, Honeywell, Charlotte, NC, USA), hydrochloric (high purity grade, Honeywell, Charlotte, NC, USA) and nitric acid (high purity grade, Honeywell, Charlotte, NC, USA) solution, assisted by microwave radiation using the Ethos Easy system (Milestone, Sorisole, Italy). The chemical analysis was done with respect to silicon, aluminium and copper content in the samples. The coordination and aggregation of the copper species were studied by UV-vis-DR spectroscopy. The measurements were performed using an Evolution 600 spectrophotometer (Thermo Scientific, Waltham, MA, USA) operating in the range of 200-900 nm 
with a resolution of $2 \mathrm{~nm}$. The reducibility of the samples was studied by temperature-programmed reduction using $\mathrm{H}_{2}$ as a reducing agent $\left(\mathrm{H}_{2}\right.$-TPR). The measurements were carried out in a fixed-bed quartz microreactor system in the temperature range of $100-700{ }^{\circ} \mathrm{C}$, with a linear heating rate of $10^{\circ} \mathrm{C} / \mathrm{min}$ in a flow of gas mixture $(5 \mathrm{~mL} / \mathrm{min})$ containing 5.0 vol. $\%$ of $\mathrm{H}_{2}$ diluted in argon. The flow of gas mixture was monitored by mass flow controller (Brooks Instrument, Hatfield, PA, USA). Before $\mathrm{H}_{2}$-TPR runs, each sample $\left(50 \mathrm{mg}\right.$ ) was outgassed in a flow of pure argon at $500{ }^{\circ} \mathrm{C}$ for $30 \mathrm{~min}$. The hydrogen conversion was analyzed using a thermal conductivity detector-TCD (VICI, Houston, TX, USA).

\subsection{Catalytic Tests}

The copper modified zeolitic samples were tested as catalysts of the selective catalytic reduction of $\mathrm{NO}$ with ammonia $\left(\mathrm{NH}_{3}-\mathrm{SCR}\right)$ as well as the catalytic oxidation of ammonia (AMOx) and $\mathrm{NO}$ to $\mathrm{NO}_{2}$ oxidation, which are reactions associated with the $\mathrm{NH}_{3}-\mathrm{SCR}$ process. Prior to the catalytic tests, each sample $(100 \mathrm{mg})$ of catalyst was placed in a fixed-bed quartz microreactor and outgassed in a flow of pure helium at $550{ }^{\circ} \mathrm{C}$ for $30 \mathrm{~min}$. Then, after cooling the reactor to $100{ }^{\circ} \mathrm{C}$, the flow of pure helium was changed for the flow of a gas mixture containing: $0.25 \mathrm{vol} \% \mathrm{NO} ; 0.25 \mathrm{vol} . \%$ $\mathrm{NH}_{3} ; 2.5$ vol. $\% \mathrm{O}_{2} ; 97.0$ vol. $\% \mathrm{He}$ (total flow rate of $40 \mathrm{~mL} / \mathrm{min}$ ) in the case of the $\mathrm{NH}_{3}$-SCR testsor $0.5 \mathrm{vol} . \% \mathrm{NH}_{3} ; 2.5 \mathrm{vol} . \% \mathrm{O}_{2} ; 97.0 \mathrm{vol} . \% \mathrm{He}$ (total flow rate of $40 \mathrm{~mL} / \mathrm{min}$ ) in the case of the AMOx test. Both in the $\mathrm{NH}_{3}-\mathrm{SCR}$ and $\mathrm{AMOx}$ tests, the reactants and product concentrations were continuously measured using a quadrupole mass spectrometer, QMS (PREVAC, Rogów, Poland), connected directly to the reactor outlet. In the case of $\mathrm{NO}$ to $\mathrm{NO}_{2}$ oxidation, the gas mixture containing $0.5 \mathrm{vol} \% \mathrm{NO}$ and $2.5 \mathrm{vol} . \% \mathrm{O}_{2}$ diluted in helium (total flow rate of $40 \mathrm{~mL} / \mathrm{min}$ ) was used. For the analysis of the $\mathrm{NO}$ and $\mathrm{NO}_{2}$ concentrations in the reaction mixture, before and after the reactor, a FTIR spectrometer Nicolet iS5 (Thermo Scientific, Waltham, MA, USA) equipped with a gas cell of $10 \mathrm{~cm}$ length was used. The spectra were recorded in the wavenumber range of $625-4000 \mathrm{~cm}^{-1}$ with a resolution of $4 \mathrm{~cm}^{-1}$ (averaged seven scans for each spectrum) every $9 \mathrm{~s}$. The bands at 1593 and $1912 \mathrm{~cm}^{-1}$ were used for the detection of $\mathrm{NO}_{2}$ and $\mathrm{NO}$, respectively. All catalytic tests were conducted with a linear temperature increase of $10^{\circ} \mathrm{C} / \mathrm{min}$. For the most promising catalyst, an additional isothermal stability test of $\mathrm{NH}_{3}$-SCR was performed. The test was conducted at $275^{\circ} \mathrm{C}$ for $15 \mathrm{~h}$ with the same composition and total flow of the reaction mixture as in polythermic catalytic tests.

\section{Conclusions}

Ferrierite and its delaminated (ITQ-6) and silica intercalated (ITQ-36) forms with different Si/Al ratios were synthetized and, after copper deposition, studied as $\mathrm{NH}_{3}-\mathrm{SCR}$ catalysts. It was shown that copper modified ITQ-6 and ITQ-36 zeolites effectively operated in $\mathrm{NH}_{3}$-SCR in much broader temperature ranges compared to the Cu-FER catalysts. For the most active catalyst, Cu-ITQ-6_30, the NO conversion above $90 \%$ was measured in the range of $250-400{ }^{\circ} \mathrm{C}$ with the selectivity to dinitrogen on the level of $98-99 \%$. High catalytic activity of the delaminated and silica intercalated zeolites in low-temperature $\mathrm{NH}_{3}$-SCR was related to the better activity of highly dispersed copper species-mainly monomeric copper cations-which were deposited into these series of zeolites. Such copper species are more active in the $\mathrm{NO}$ to $\mathrm{NO}_{2}$ oxidation compared to aggregated copper oxide species present in microporous ferrierites. $\mathrm{NO}_{2}$ was necessary for fast-SCR $\left(2 \mathrm{NH}_{3}+\mathrm{NO}+\mathrm{NO}_{2}\right.$ $\rightarrow 2 \mathrm{~N}_{2}+3 \mathrm{H}_{2} \mathrm{O}$ ), which is one of the main pathways of low-temperature $\mathrm{NH}_{3}$-SCR. In the high temperature $\mathrm{NH}_{3}-\mathrm{SCR}$, delaminated and silica intercalated zeolites with higher aluminum content presented better catalytic performance compared to low-alumina Cu-ITQ-6_50 and Cu-ITQ-36_50. This effect was related to the higher activity of low-alumina zeolites in the side process of direct ammonia oxidation, which decreased the efficiency of high-temperature $\mathrm{NH}_{3}-\mathrm{SCR}$. Thus, the catalysts with a higher concentration of acid sites are possibly able to more effectively protect chemisorbed ammonia against oxidation. The stability $\mathrm{NH}_{3}$-SCR test for Cu-ITQ-6, conducted at $275^{\circ} \mathrm{C}$ for $15 \mathrm{~h}$, shows only small changes in the NO conversion and selectivity towards dinitrogen, proving the high 
stability of this catalyst under reaction conditions. Taking into account the results of the presented studies, it could be concluded that delaminated Cu-ITQ-6_30 is a very promising catalyst for the low-temperature $\mathrm{NH}_{3}-\mathrm{SCR}$ reaction.

Author Contributions: A.Ś.: Methodology, Investigation, Data curation, Writing-review \& editing; A.K.: Investigation; M.R.: Investigation; U.D.: Methodology, Investigation, Supervision, Writing-review \& editing; A.E.P.: Investigation; L.C.: Conceptualization, Methodology, Project administration, Supervision, Writingoriginal draft, Writing-review \& editing. All authors have read and agree to the published version of the manuscript.

Funding: This work was supported by the National Science Centre-Poland [2016/21/B/ST5/00242].

Acknowledgments: The studies financed by the National Science Centre-Poland [2016/21/B/ST5/00242]. A.Ś. has been partly supported by the EU Project POWR.03.02.00-00-I004/16. U.D. acknowledges the Spanish Government for the funding [MAT2017-82288-C2-1-P]. Part of the research was done with equipment purchased in the frame of the European Regional Development Fund (Polish Innovation Economy Operational Program [POIG.02.01.00-12-023/08).

Conflicts of Interest: The authors declare no conflicts of interest.

\section{References}

1. Kowalczyk, A.; Święś, A.; Gil, B.; Rutkowska, M.; Piwowarska, Z.; Borcuch, A.; Michalik, M.; Chmielarz, L. Effective catalysts for the low-temperature $\mathrm{NH}_{3}$-SCR process based on MCM-41 modified with copper by template ion-exchange (TIE) method. Appl. Catal. B Environ. 2018, 237, 927-937. [CrossRef]

2. Busca, G.; Lietti, L.; Ramis, G.; Berti, F. Chemical and mechanistic aspects of the selective catalytic reduction of NO by ammonia over oxide catalysts: A review. Appl. Catal. B Environ. 1998, 18, 1-36. [CrossRef]

3. Kompio, P.G.; Brückner, A.; Hipler, F.; Auer, G.; Löffler, E.; Grünert, W. A new view on the relations between tungsten and vanadium in $\mathrm{V}_{2} \mathrm{O}_{5} \mathrm{WO}_{3} / \mathrm{TiO}_{2}$ catalysts for the selective reduction of $\mathrm{NO}$ with $\mathrm{NH}_{3}$. J. Catal. 2012, 286, 237-247. [CrossRef]

4. Lee, S.M.; Kim, S.S.; Hong, S.C. Systematic mechanism study of the high temperature SCR of $\mathrm{NO}_{X}$ by $\mathrm{NH}_{3}$ over a $\mathrm{W} / \mathrm{TiO}_{2}$ catalyst. Chem. Eng. Sci. 2012, 79, 177-185. [CrossRef]

5. Mladenovic, M.; Paprika, M.; Marinković, A. Denitrification techniques for biomass combustion. Renew. Sustain. Energy Rev. 2018, 82, 3350-3364. [CrossRef]

6. Rutkowska, M.; Pacia, I.; Basag, S.; Kowalczyk, A.; Piwowarska, Z.; Duda, M.; Tarach, K.A.; Góra-Marek, K.; Michalik, M.; Díaz, U.; et al. Catalytic performance of commercial Cu-ZSM-5 zeolite modified by desilication in $\mathrm{NH}_{3}$-SCR and $\mathrm{NH}_{3}$-SCO processes. Microporous Mesoporous Mater. 2017, 246, 193-206. [CrossRef]

7. Rutkowska, M.; Diaz, U.; Palomares, A.E.; Chmielarz, L. Cu and Fe modified derivatives of 2D MWW-type zeolites (MCM-22, ITQ-2 and MCM-36) as new catalysts for DeNO x process. Appl. Catal. B Environ. 2015, 168, 531-539. [CrossRef]

8. Jodłowski, P.; Kuterasiński, Ł.; Jędrzejczyk, R.; Chlebda, D.; Gancarczyk, A.; Basag, S.; Chmielarz, L. DeNOx Abatement Modelling over Sonically Prepared Copper USY and ZSM-5 Structured Catalysts. Catalysts 2017, 7, 205. [CrossRef]

9. Boroń, P.; Chmielarz, L.; Dzwigaj, S. Influence of Cu on the catalytic activity of FeBEA zeolites in SCR of NO with $\mathrm{NH}_{3}$. Appl. Catal. B Environ. 2015, 168, 377-384. [CrossRef]

10. Martín, N.; Boruntea, C.R.; Moliner, M.; Corma, A. Efficient synthesis of the Cu-SSZ-39 catalyst for DeNOx applications. Chem. Commun. 2015, 51, 11030-11033. [CrossRef]

11. Shan, Y.; Sun, Y.; Du, J.; Zhang, Y.; Shi, X.; Yu, Y.; Shan, W.; He, H. Hydrothermal aging alleviates the inhibition effects of $\mathrm{NO}_{2}$ on Cu-SSZ-13 for $\mathrm{NH}_{3}$-SCR. Appl. Catal. B Environ. 2020, 275, 119105. [CrossRef]

12. Clark, A.H.; Nuguid, R.J.G.; Steiger, P.; Marberger, A.; Petrov, A.W.; Ferri, D.; Nachtegaal, M.; Kröcher, O. Selective Catalytic Reduction of $\mathrm{NO}$ with $\mathrm{NH}_{3}$ on $\mathrm{Cu}-\mathrm{SSZ}-13$ : Deciphering the Low and High-temperature Rate-limiting Steps by Transient XAS Experiments. ChemCatChem 2020, 12, 1429-1435. [CrossRef]

13. Shan, Y.; Du, J.; Yu, Y.; Shan, W.; Shi, X.; He, H. Precise control of post-treatment significantly increases hydrothermal stability of in-situ synthesized Cu-zeolites for $\mathrm{NH}_{3}$-SCR reaction. Appl. Catal. B Environ. 2020, 266, 118655. [CrossRef] 
14. Marosz, M.; Samojeden, B.; Kowalczyk, A.; Rutkowska, M.; Motak, M.; Diaz, U.M.; Palomares, A.E.; Chmielarz, L. MCM-22, MCM-36, and ITQ-2 Zeolites with Different Si/Al Molar Ratios as Effective Catalysts of Methanol and Ethanol Dehydration. Materials 2020, 13, 2399. [CrossRef] [PubMed]

15. Chmielarz, L.; Jabłońska, M. Advances in selective catalytic oxidation of ammonia to dinitrogen: A review. RSC Adv. 2015, 5, 43408-43431. [CrossRef]

16. De Pietre, M.K.; Bonk, F.A.; Rettori, C.; Garcia, F.; Pastore, H.O. [V,Al]-ITQ-6: Novel porous material and the effect of delamination conditions on V sites and their distribution. Microporous Mesoporous Mater. 2011, 145, 108-117. [CrossRef]

17. Radko, M.; Rutkowska, M.; Kowalczyk, A.; Mikrut, P.; Święs, A.; Díaz, U.; Palomares, A.E.; Macyk, W.; Chmielarz, L. Catalytic oxidation of organic sulfides by $\mathrm{H}_{2} \mathrm{O}_{2}$ in the presence of titanosilicate zeolites, Micropor. Mesopor. Mater. 2020, 302, 110219. [CrossRef]

18. Schreyeck, L.; Caullet, P.; Mougenel, J.; Guth, J.; Marler, B. PREFER: A new layered (alumino) silicate precursor of FER-type zeolite. Microporous Mater. 1996, 6, 259-271. [CrossRef]

19. Jin, F.; Chang, C.-C.; Yang, C.-W.; Lee, J.-F.; Jang, L.-Y.; Cheng, S. New mesoporous titanosilicate MCM-36 material synthesized by pillaring layered ERB-1 precursor. J. Mater. Chem. A 2015, 3, 8715-8724. [CrossRef]

20. Rutkowska, M.; Borcuch, A.; Marzec, A.; Kowalczyk, A.; Samojeden, B.; Moreno, J.; Díaz, U.; Chmielarz, L. Influence of iron aggregation on the catalytic performance of desilicated MFI in the DeNOx process. Microporous Mesoporous Mater. 2018, 109114. [CrossRef]

21. Maddalena, R.; Hall, C.; Hamilton, A. Effect of silica particle size on the formation of calcium silicate hydrate [C-S-H] using thermal analysis. Thermochim. Acta 2019, 672, 142-149. [CrossRef]

22. Thommes, M.; Kaneko, K.; Neimark, A.V.; Olivier, J.P.; Rodriguez-Reinoso, F.; Rouquerol, J.; Sing, K.S. Physisorption of gases, with special reference to the evaluation of surface area and pore size distribution (IUPAC Technical Report). Pure Appl. Chem. 2015, 87, 1051-1069. [CrossRef]

23. Ramli, Z.; Aishikin, N.; Yusoff, M.; Hamdan, H. Delaminated zeolite, ITQ-6 as heterogeneous catalyst for Friedel Crafts alkylation. MJAS 2007, 11, 84-92.

24. Ishihara, A.; Hashimoto, T.; Nasu, H. Large Mesopore Generation in an Amorphous Silica-Alumina by Controlling the Pore Size with the Gel Skeletal Reinforcement and Its Application to Catalytic Cracking. Catalysts 2012, 2, 368-385. [CrossRef]

25. Thommes, M. Physical Adsorption Characterization of Nanoporous Materials. Chem. Ing. Tech. 2010, 82, 1059-1073. [CrossRef]

26. Hu, H.; Ke, M.; Zhang, K.; Liu, Q.; Yu, P.; Liu, Y.; Li, C.; Liu, W. Designing ferrierite-based catalysts with improved properties for skeletal isomerization of n-butene to isobutene. RSC Adv. 2017, 7, 31535-31543. [CrossRef]

27. Domokos, L.; Lefferts, L.; Seshan, K.; Lercher, J. The importance of acid site locations for n-butene skeletal isomerization on ferrierite. J. Mol. Catal. A Chem. 2000, 162, 147-157. [CrossRef]

28. Cañizares, P.; Carrero, A. Dealumination of ferrierite by ammonium hexafluorosilicate treatment: Characterization and testing in the skeletal isomerization of n-butene. Appl. Catal. A Gen. 2003, 248, 227-237. [CrossRef]

29. Wichterlova, B.; Tvaruzkova, Z.; Sobalík, Z.; Sarv, P. Determination and properties of acid sites in H-ferrierite. Microporous Mesoporous Mater. 1998, 24, 223-233. [CrossRef]

30. Thibault-Starzyk, F.; Stan, I.; Abelló, S.; Bonilla, A.; Thomas, K.; Fernandez, C.; Gilson, J.-P.; Pérez-Ramírez, J. Quantification of enhanced acid site accessibility in hierarchical zeolites-The accessibility index. J. Catal. 2009, 264, 11-14. [CrossRef]

31. Macina, D.; Piwowarska, Z.; Tarach, K.A.; Góra-Marek, K.; Ryczkowski, J.; Chmielarz, L. Mesoporous silica materials modified with alumina polycations as catalysts for the synthesis of dimethyl ether from methanol. Mater. Res. Bull. 2016, 74, 425-435. [CrossRef]

32. Huo, Q.; Margolese, D.I.; Stucky, G.D. Surfactant Control of Phases in the Synthesis of Mesoporous Silica-Based Materials. Chem. Mater. 1996, 8, 1147-1160. [CrossRef]

33. Martins, L.; Peguin, R.; Wallau, M.; Urquieta, G. Cu-, Co-, Cu/Ca- and Co/Ca-exchanged ZSM-5 zeolites: Activity in the reduction of NO with methane or propane. Adv. Pharmacol. 2004, 154, 2475-2483. [CrossRef]

34. Carniti, P.; Gervasini, A.; Modica, V.H.; Ravasio, N. Catalytic selective reduction of NO with ethylene over a series of copper catalysts on amorphous silicas. Appl. Catal. B Environ. 2000, 28, 175-185. [CrossRef] 
35. Minchev, C.; Kohn, R.; Tsoncheva, T.; Dimitrov, M.; Fröba, M. Preparation and characterization of copper oxide modified MCM-41 molecular sieves. Adv. Pharmacol. 2001, 135, 253. [CrossRef]

36. Martins, L.; Peguin, R.P.S.; Urquiet-González, E.A. Cu and Co exchanged ZSM-5 zeolites: Activity towards NO reduction and hydrocarbon oxidation. Quimica Nova 2006, 29, 223-229. [CrossRef]

37. Sullivan, J.A.; Cunningham, J. Selective catalytic reduction of $\mathrm{NO}$ with $\mathrm{C}_{2} \mathrm{H}_{4}$ over $\mathrm{Cu} / \mathrm{ZSM}-5$ : Influences of oxygen partial pressure and incorporated rhodia. Appl. Catal. B Environ. 1998, 15, 275-289. [CrossRef]

38. Yang, X.; Wang, X.; Qiao, X.; Jin, Y.; Fan, B. Effect of Hydrothermal Aging Treatment on Decomposition of NO by Cu-ZSM-5 and Modified Mechanism of Doping Ce against This Influence. Materials 2020, 13, 888. [CrossRef]

(C) 2020 by the authors. Licensee MDPI, Basel, Switzerland. This article is an open access article distributed under the terms and conditions of the Creative Commons Attribution (CC BY) license (http://creativecommons.org/licenses/by/4.0/). 